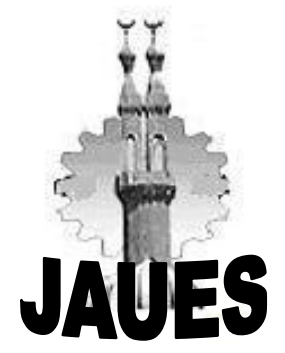

Journal of Al Azhar University Engineering Sector

Vol. 14, No. 52, July 2019, 1173-1188

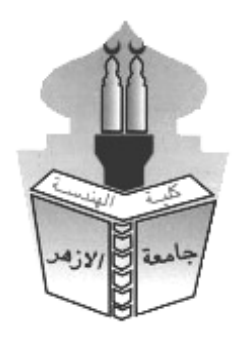

\title{
EVALUATION OF THE CURRENT SITUATION OF THE PEDESTRIANS' PATHWAYS IN THE EGYPTIAN CITIES
}

\author{
Shukri Mohammed Hassanin El Bellahy \\ Department Of Architecture, Misr Higher Institute Of Engineering And Technology - Mansoura \\ smhelbellahy@gmail.com
}

\begin{abstract}
:
Currently, many of the Pedestrians pathways in the Egyptian cities streets characterized by its incompatibility with the pedestrians pathways quality indicators, because of the aggression through removing some components and adding other components by the property owners, shops holders and street vendors, which led to the walking difficulty for many pedestrians. This research aims to evaluate the current situation of the pedestrians' pathways quality in the Egyptian cities streets using quality indicators of the pedestrians' pathways, as well as matching its current situation with laws and scientific standards for the pedestrians' pathways design in the cities streets. The research concluded that the evaluation of the current situation of the pedestrians pathways in the Egyptian cities streets, revealed violations in the pedestrians pathways according to quality indicators, as well as the laws and scientific standards, which organize design, execution and use of these pathways in the Streets of Egyptian cities. The research recommends the necessity to modernize and improve the urban quality of the pedestrians pathways in all Egyptian cities streets, in addition to take into consideration the accuracy and honesty when building permits are issued which affect the shape and dimensions of pedestrians pathways in the streets and squares of Egyptian cities, as well as the continuous supervision that what are executed are identical to what are approved in the building
\end{abstract} permit documents.

Key words: Comprehensive access, Quality indicators of Pedestrians pathways, Streets design codes, Building laws.

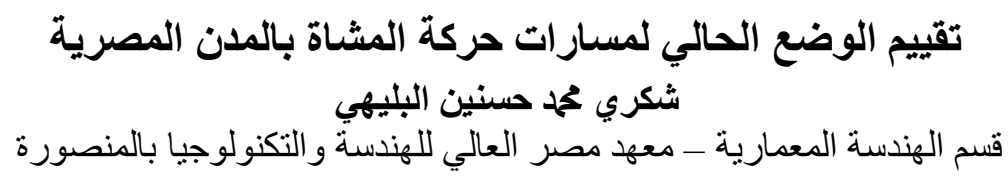

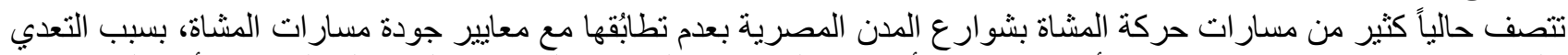

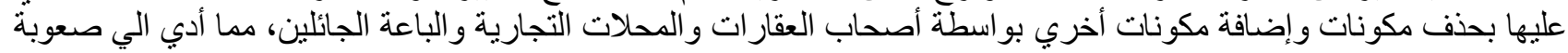

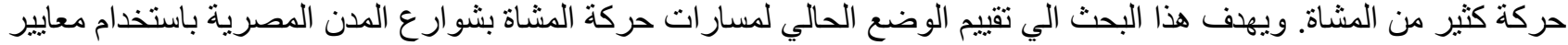

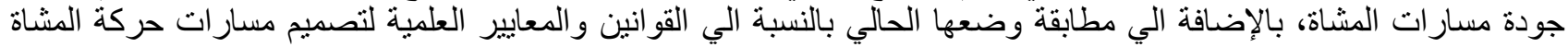

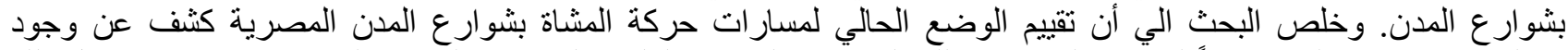

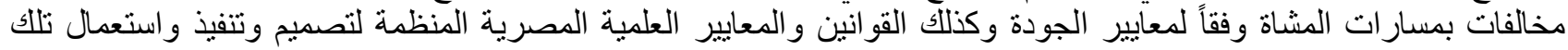

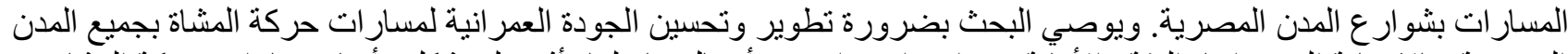

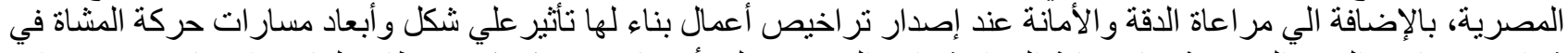
شوارع وميادين المدن المصرية، بالإضافة الي الإشر اف المستمر علي أن ما يتم تنفيذه يكون مطابق لما يتم اعتمادئ الإه في مستندات ترخيص البناء. 


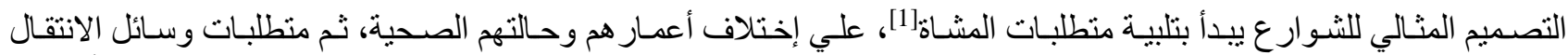

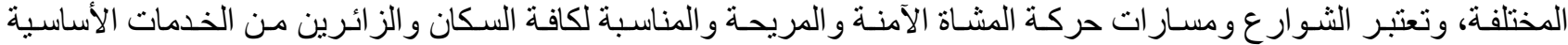

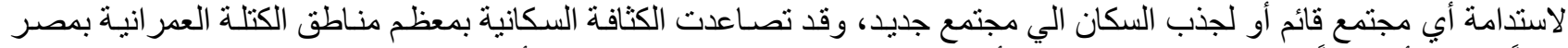

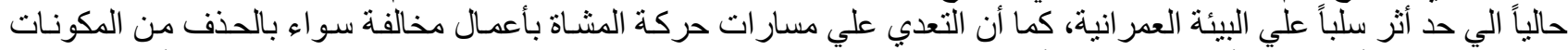

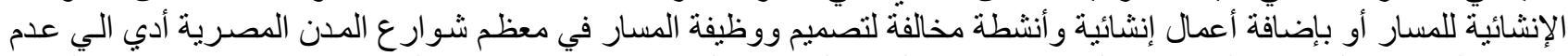

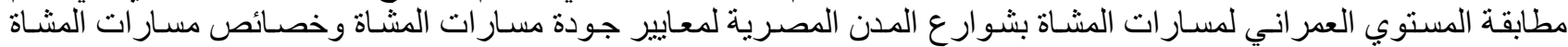

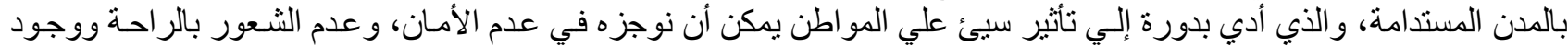

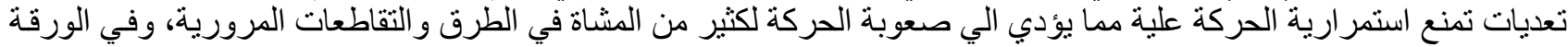

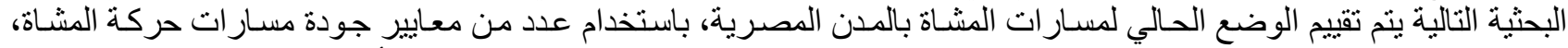

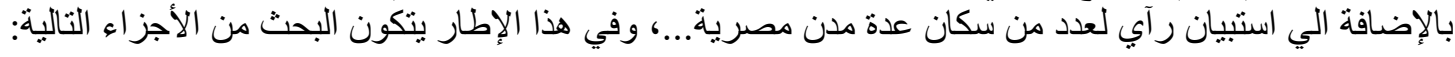

1-1

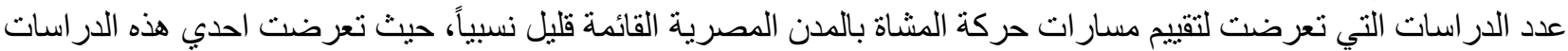

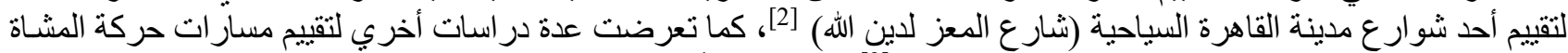

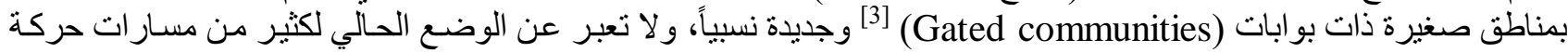

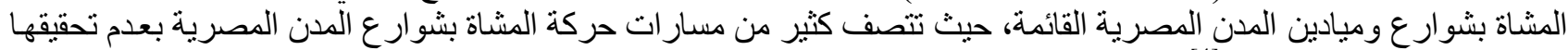

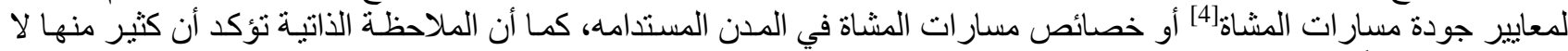

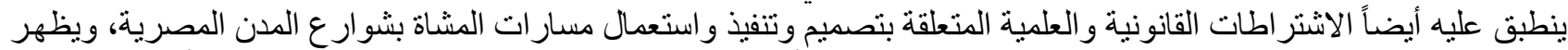

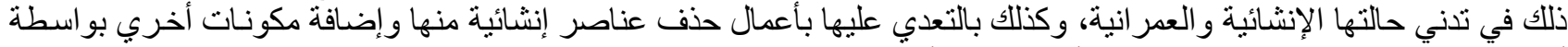

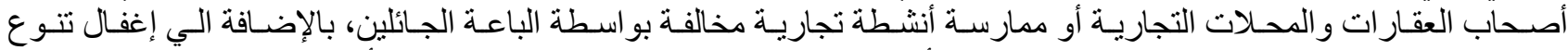

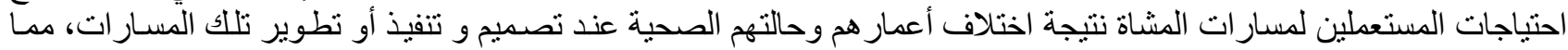

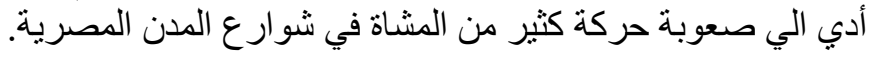

2-1

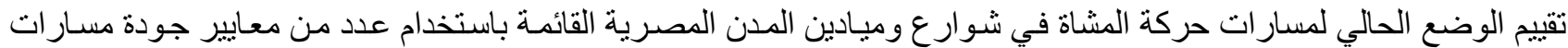

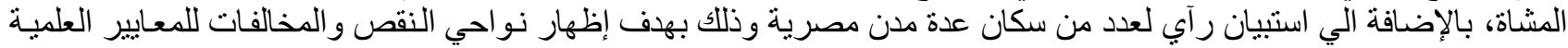

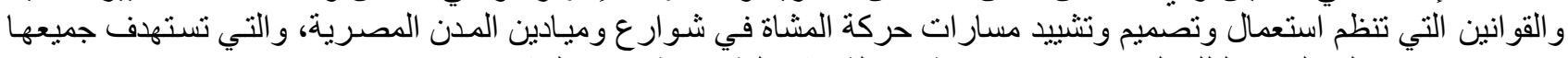

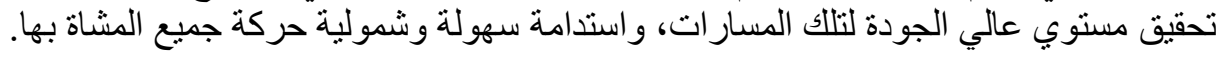

اعتمد البحثث علية البحت عدة مناهج بحثية منها المنهج الاستقرائي [5]، حيث تم قر اعة ومر اجعة الدر اسـات العلميـة السـابقة التي تعرضت

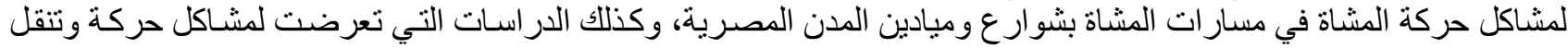

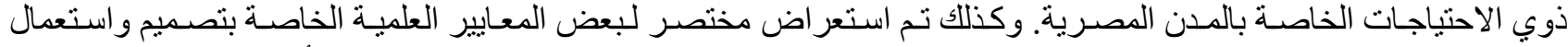

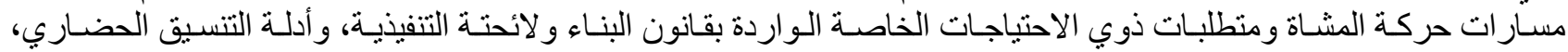

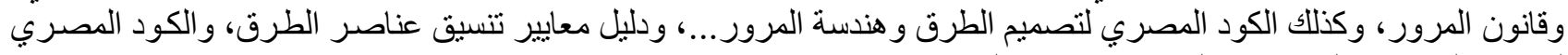

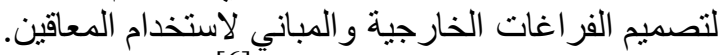

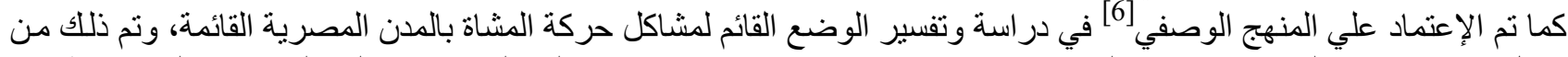

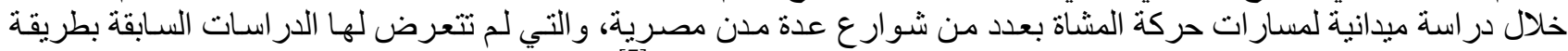

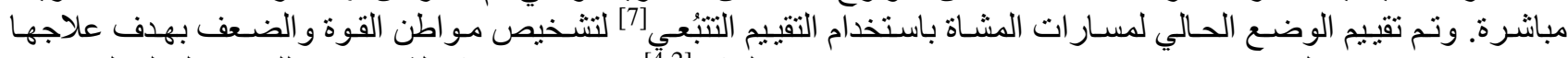

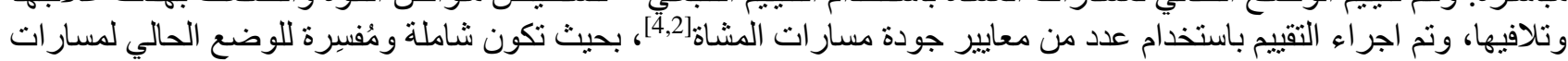

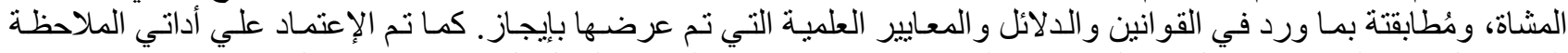

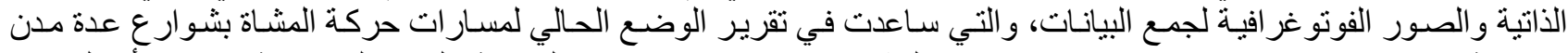

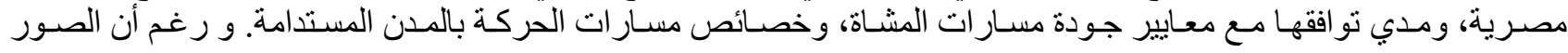


الفونو غر افية لأماكن محدودة في عدة مدن مصرية إلا أنها تعبر عن مشكلة متكررة في كثير من مناطق المدن المصدرية. بالإضـافة

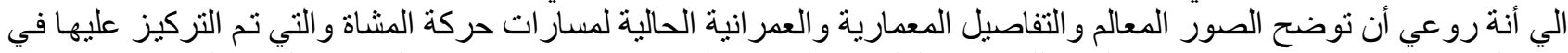

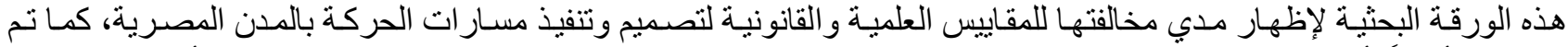

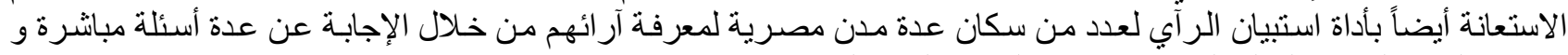
و اضحة لتقييم الوضع الحاد الحالي لجودة مسار الري لعدد المشاة بالمدن المصرية.

2 مفاهيم و مصطات مكات

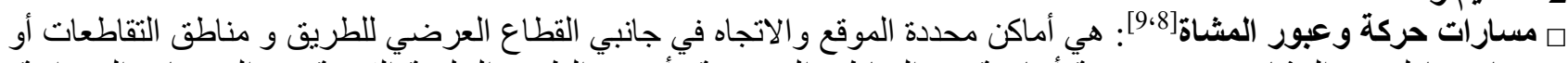

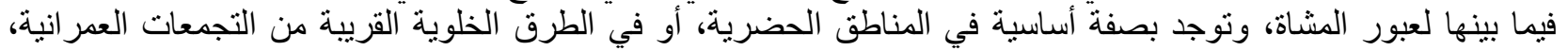

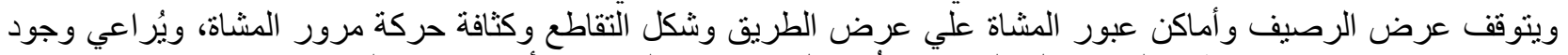

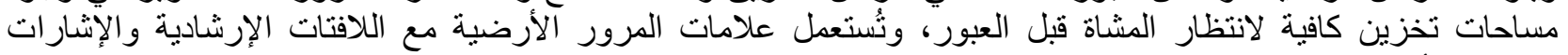

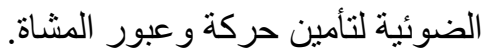

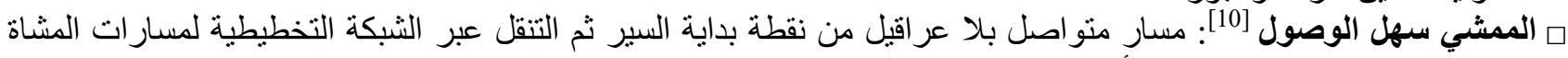

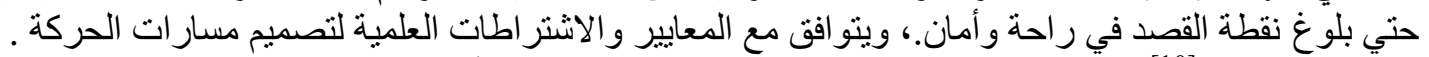

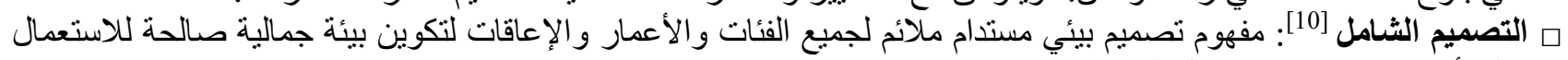

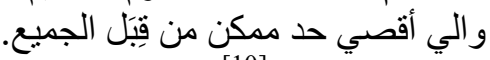

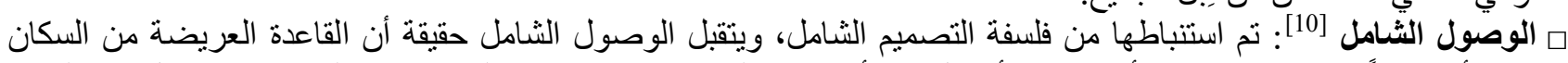

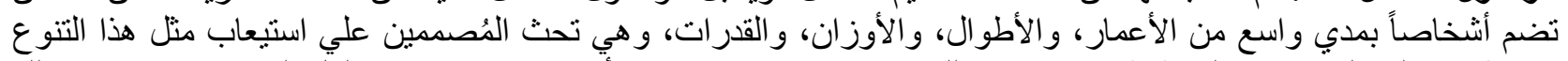

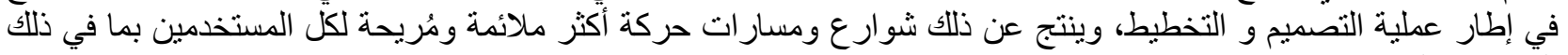
المُعاقين و المُسنين.

3

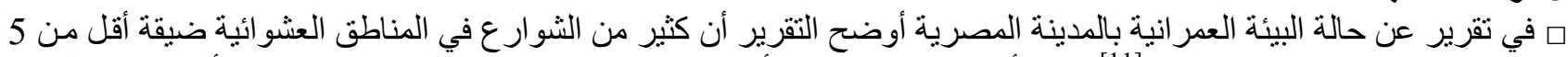

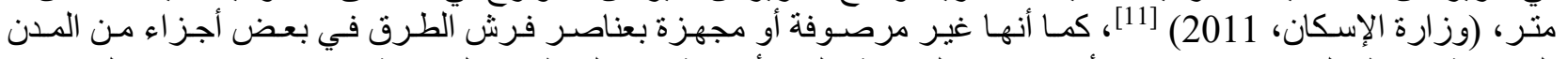

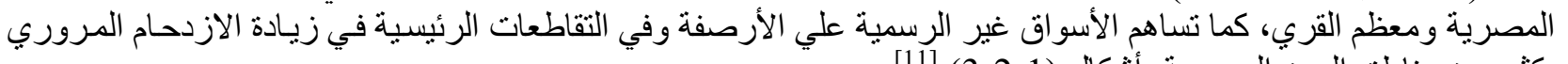

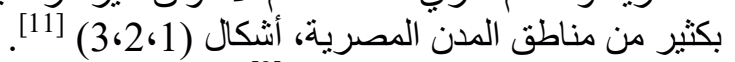

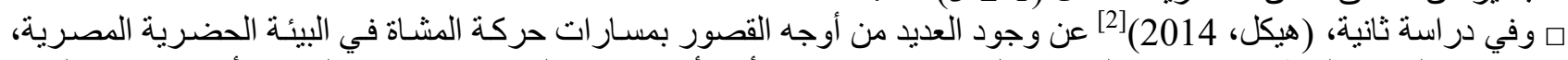

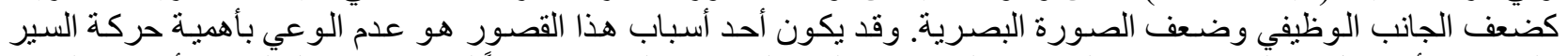

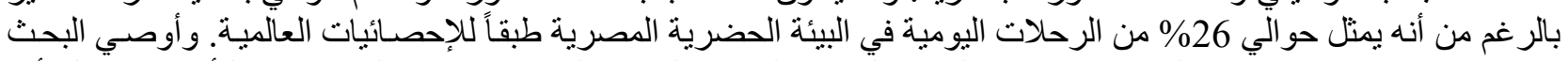

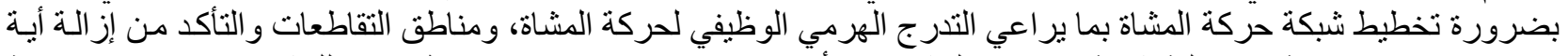

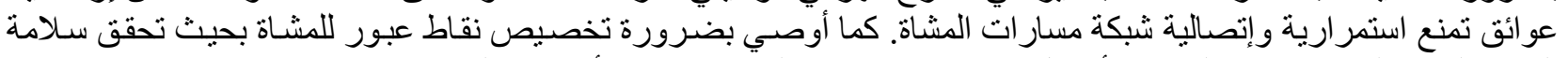

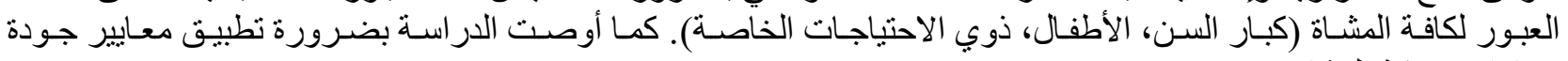
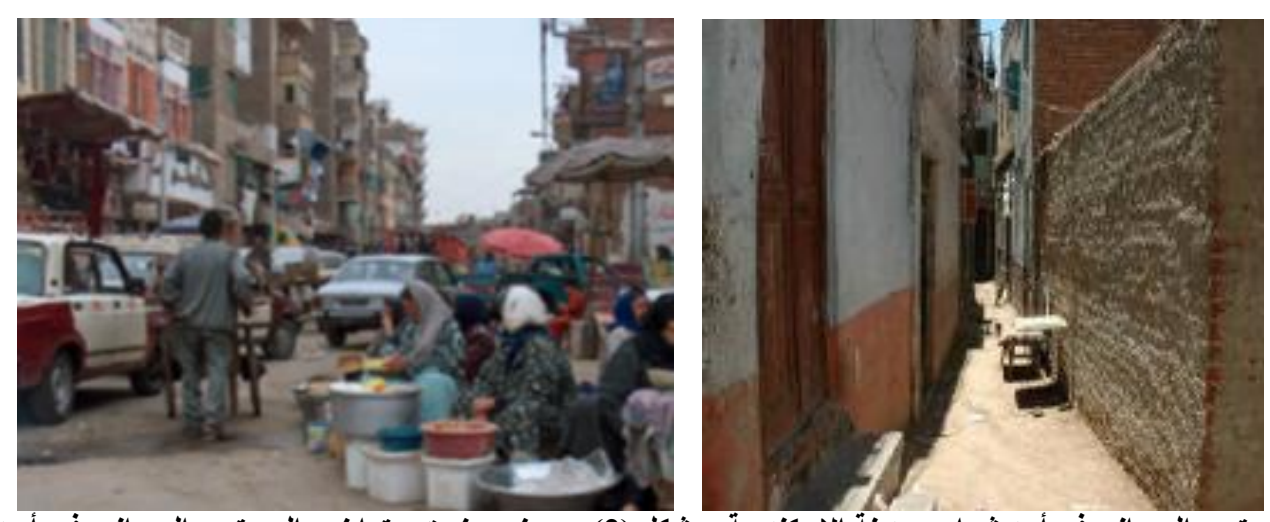

مسار ات حركة المشاة.

شكل (1) : يوضح ضيق وتو اضع المستوي العمر اني في أحد شوارع مدينة الإسكندرية، وشكل (2) : يوضيح ضيق وتواضيع المستوي العمراني في أحد

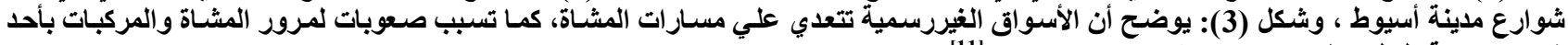

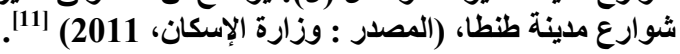




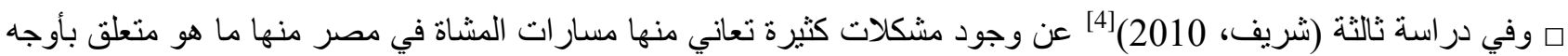

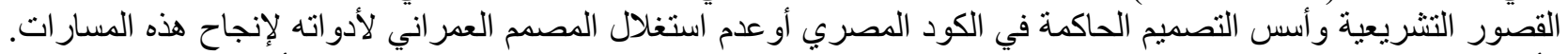

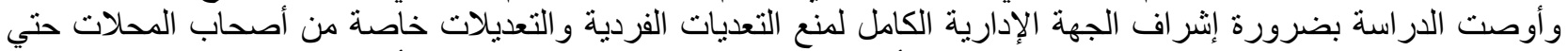

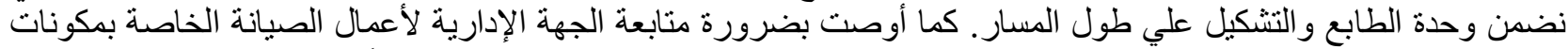

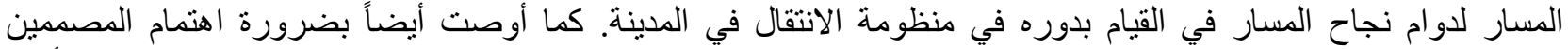

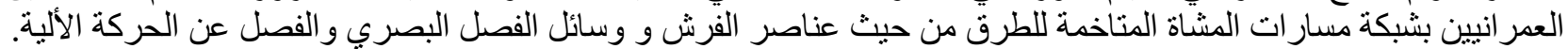

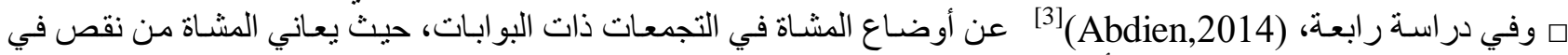

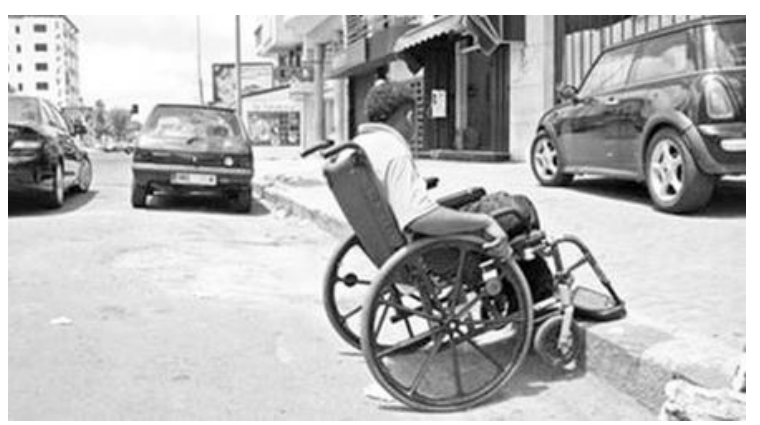

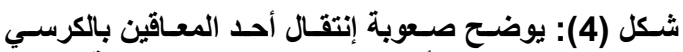

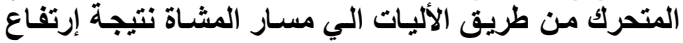

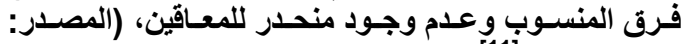

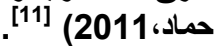

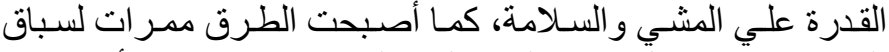

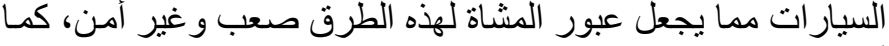

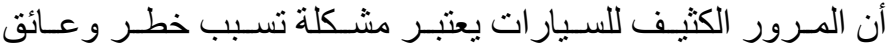

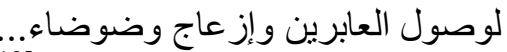

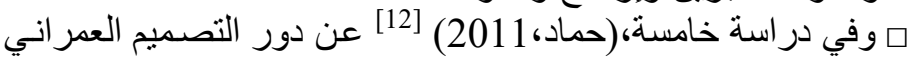

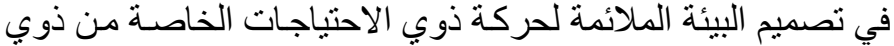

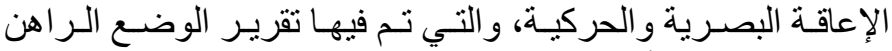

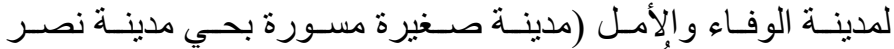

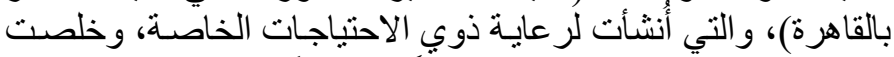

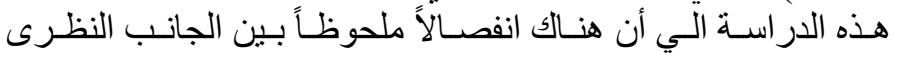

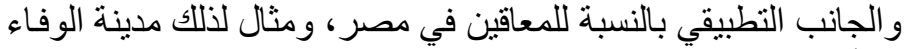

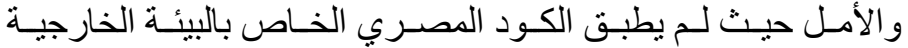

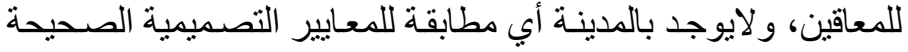

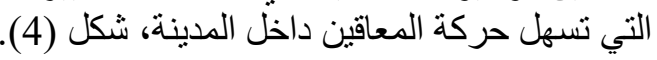

\section{4 المعايير القانونية والعلمية المصرية لتصميم واستعمال مسارات حركة المشاة بالطرق والمياديادين.}

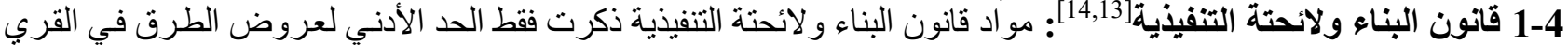

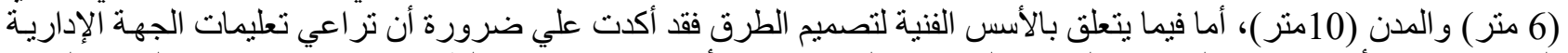

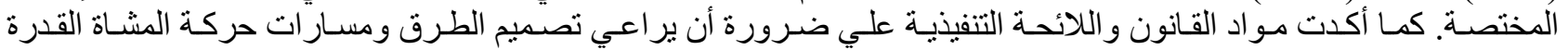

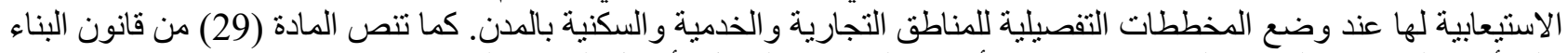

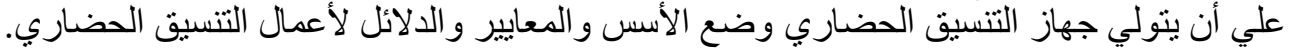

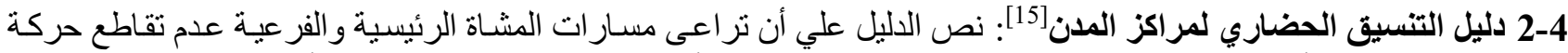

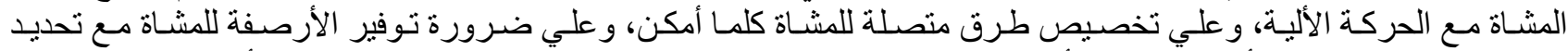

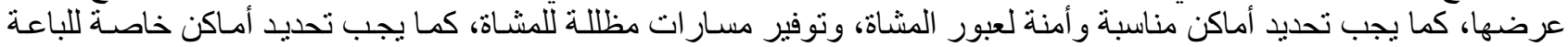

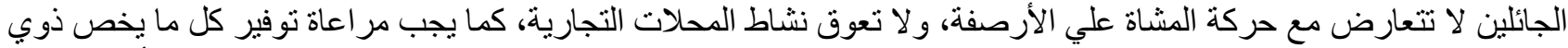

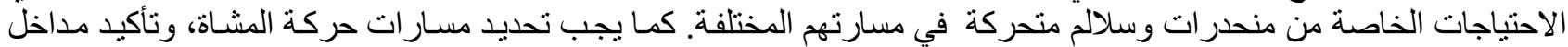

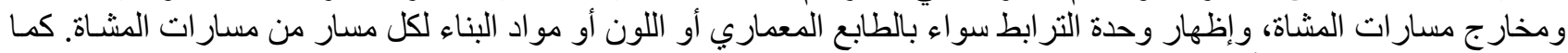

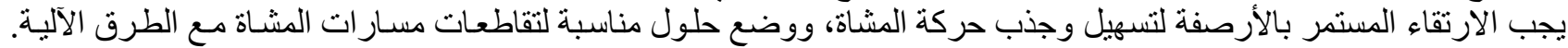

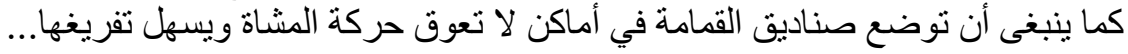

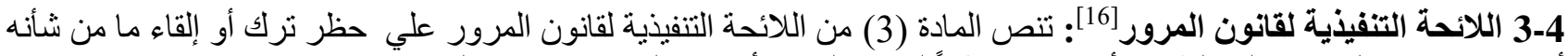

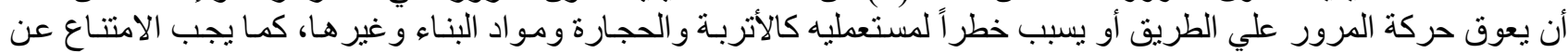

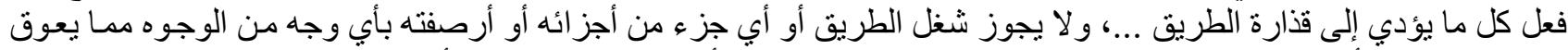

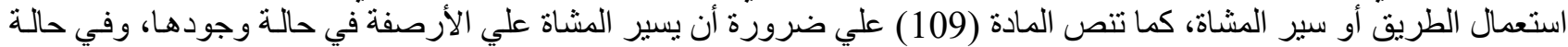
عدم وجودها يسير في جانب الطريق ال... 


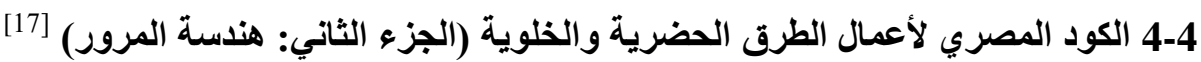

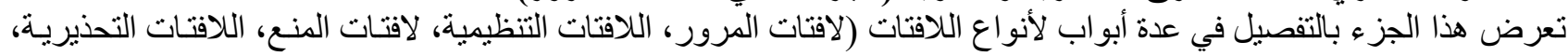

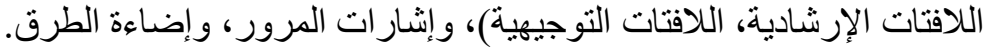

جلول (1) يعرض عروض الأرصفة المطلوبـة تبعاً لحجم المشـاة،

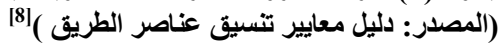

\begin{tabular}{|c|c|}
\hline ألق عرضف & كثافة المشاة \\
\hline 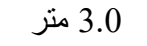 & صغيرة (أقل من 30 شخص في الدقيقة) \\
\hline 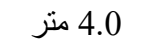 & متوسطة (من 31 الي 80 شخص في الدقيقة) \\
\hline 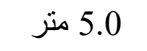 & عالية (من 81 الي 120 شخص في الدقيقة) \\
\hline 6 6.0 منر & كثيفة (أكثر من 120 شخص في الدقيقة) \\
\hline
\end{tabular}

5-4 5ليل معايير تنسيق عناصر الطريق الطيق

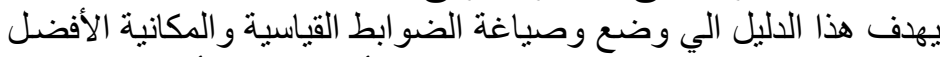

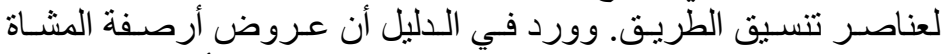

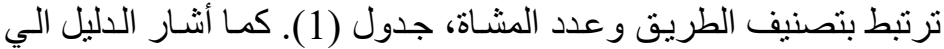

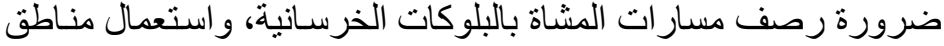

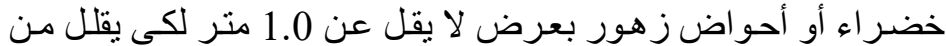

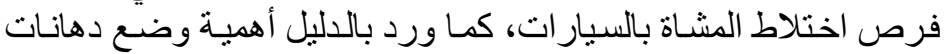

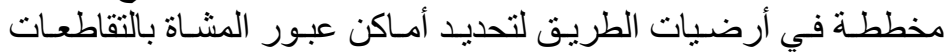
السطحية للطرق.

6-4 الكود المصري لأسس تصميم واثتراطات تنفيذ أعمال الطرق الحضرية (الجزء الثالث: التصميم الهندسي للطرق) [9]

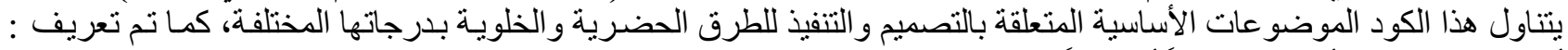
جدول (2) يعرض القيم الاسترشادية لأقل عرض للأرصفة طبقاً لتصنيف الطرق

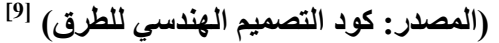

\begin{tabular}{|c|c|c|c|c|}
\hline محلي & تجميعي محلي & شرياني ثنانوي & شرياني رئيسي & تصنيف الطرق \\
\hline 1.5 & 1.5 & 2.5 & 2.5 & عرض الأرصفة (متر) \\
\hline
\end{tabular}

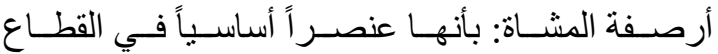

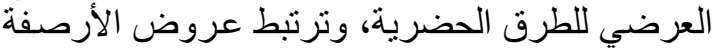

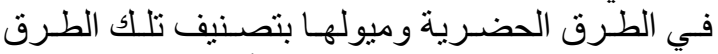
ويتحدد العرض المناسب من خلال أحجام حركة المشنساة

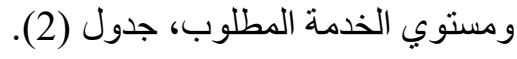

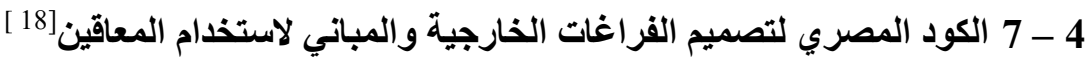

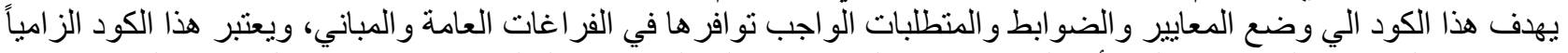

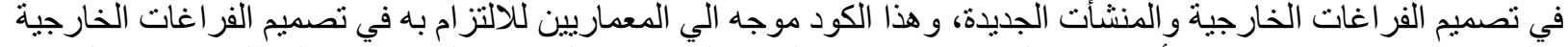

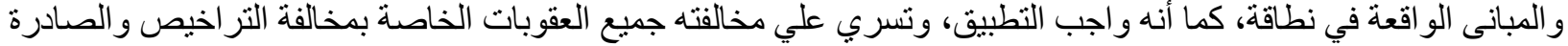
بموجب قانون 101 لسنة 1996 و لائحته التنفيذية، ويضم الجزئ ولئ التالي بعض منطلبات تصميم مسار ات الحركة الو اردة به :

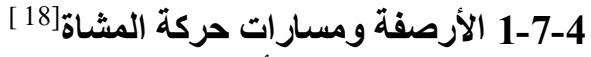

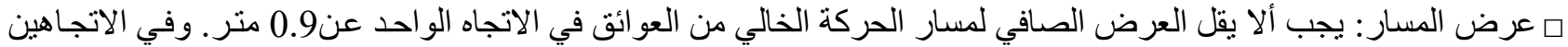

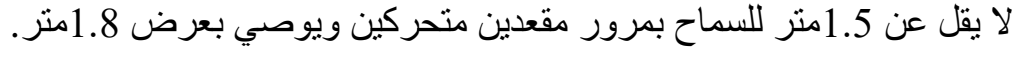

هأرضية المسار : يجب أن يكون السطح متصلاً مستوياً بدون نتوءات تعوق الحركة وذا ملمس لا يساعد علي الانزلاق. 口ميل المسار: يجب ألا يزيد ميل المسار عن 1: 20 وفي حالة زيادته عن ذلك يجب تصميمه كمنحدر مـع مر اعاة ألا تزيد نسبة الانحدار عن 1: 12 .

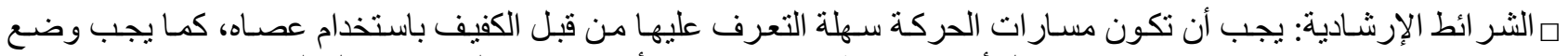

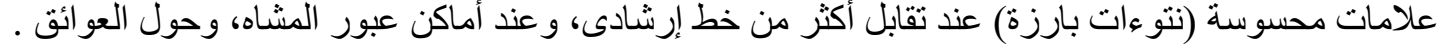
ه بردورات الأرصفة: يجب ألا يقل إرتفاع بردورة الرصيف عن 0.1 منر، و ألا يزيد عن 0.15 متر. 口 حواجز الأمان: في حالة وجود فرق في المنسوب يزيد عن 2سم بين المسار و السطح المحيط به، يلزم استخدام حواجز للحماية . ه القو ائم الثابتة: يجب أن تطلي القو ائم الثابتة بألوان و اضحة أو تغطي بشر ائط ملونة وأن تكون المسافات بينها حو الي 1.2مثر . 


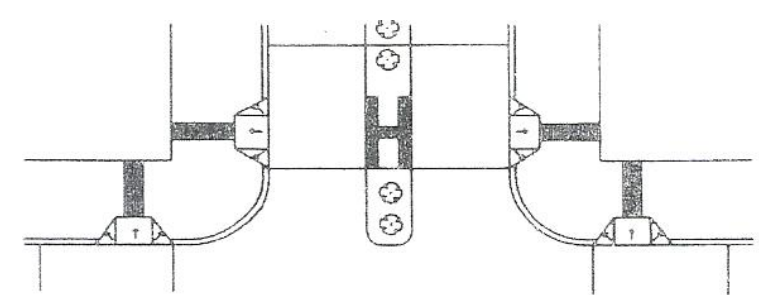

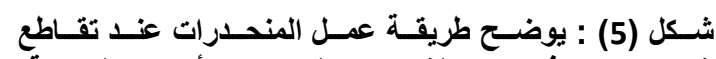

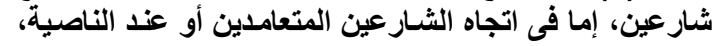

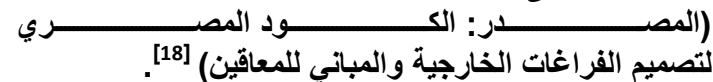

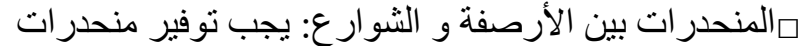
مناسبة لتسهيل الحركة من و الي الرصبف واعن وهي أحد ثلاثنة أنواع:

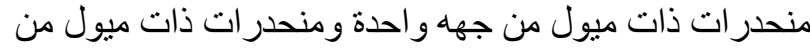

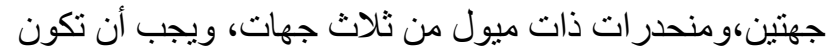

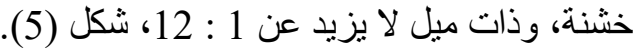

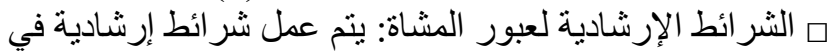

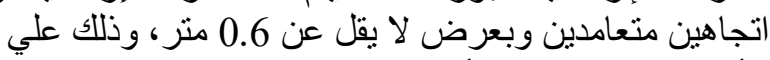

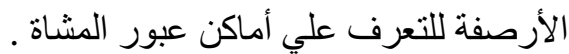

口 إشـار ات المرور: يجب تزويد إثـار ات المرور الضورئية للمشاه بوسائل مسمو عة لخدمة المكفوفين، كما يجب وضـع أزرار التحكم

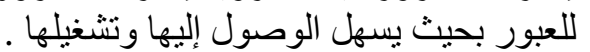
ه الجزر الوسطي للطرق: يجب ألا يقل عرض الجزيرة الوسطي للطريق عن 1.5متر.

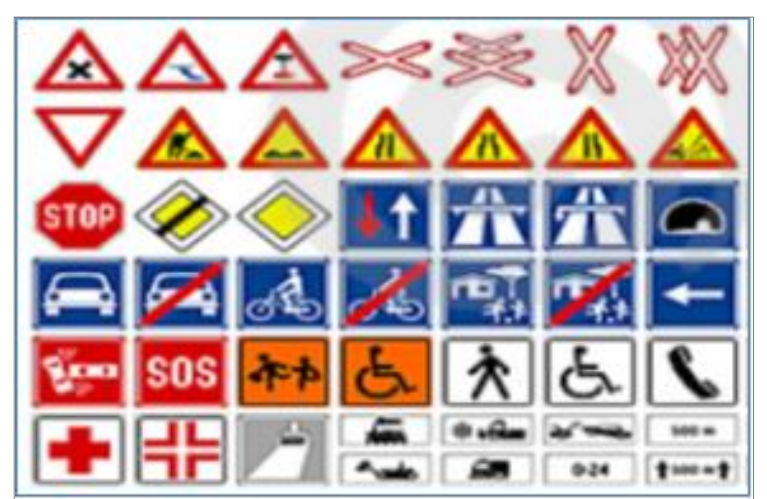

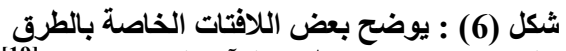

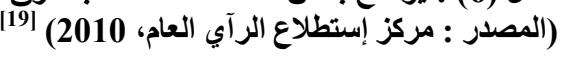

3-7-4

تستخدم اللافتات لتسهيل وتتظيم حركة المشـاة والسيار ات في الطرق

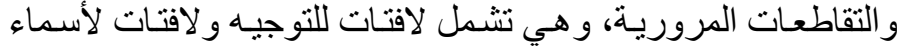

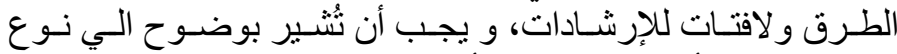

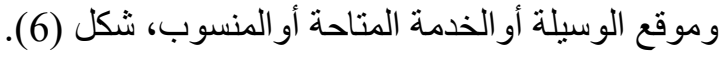

\section{5 الإنتقال في المدن المستدامة}

1-5 حركة المثاة في المدن المستدامة

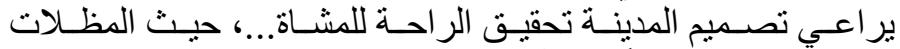

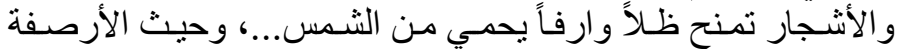

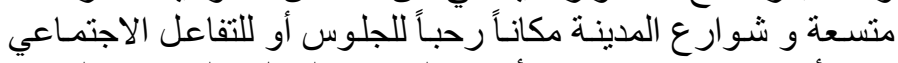

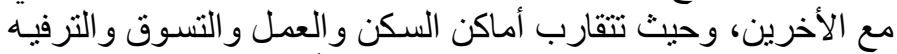

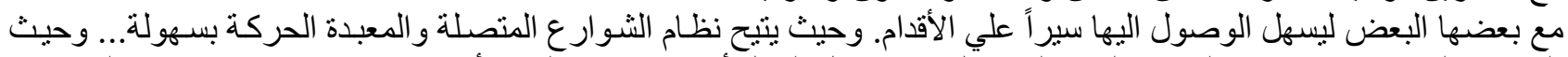
اللافتات الو اضحة و إثار ات المرور المجدولة بشكل جيد تجعل التقل أيسر و وقت السفر أقصر ....، وحيث تقع مواقف واقف السيارات

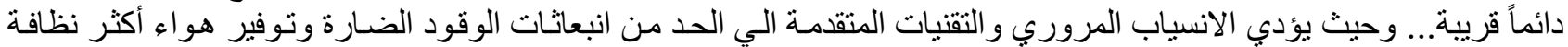

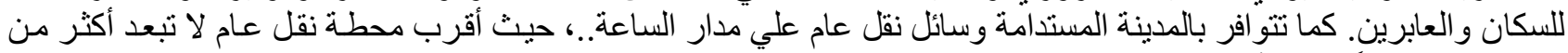
خمس دقائق سيراً علي الأقدام من السكن.

2-5 وسائل إنجاز الانتقال المستدام

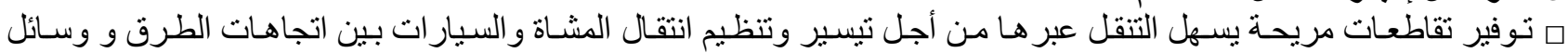

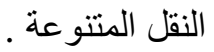
ه تركيـب إثـار ات مروريـة لتـوفير معـابر للمشـاة في وسـط التكتلات السكنية الطويلـة و عند نقـاط العبـور الرئيسية، كالمـدارس

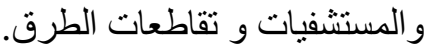

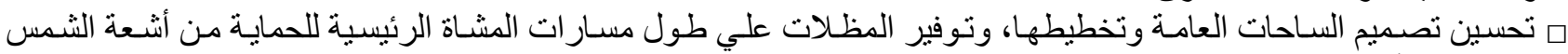

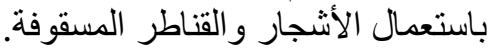

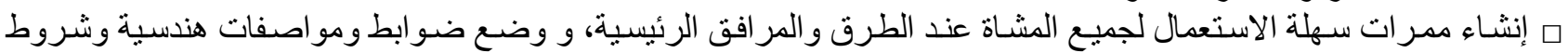

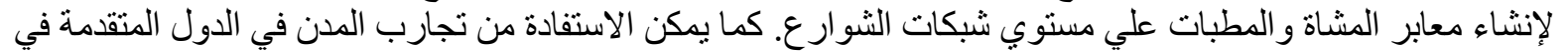

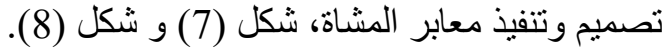

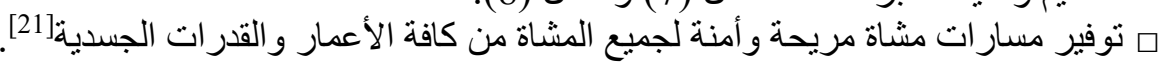



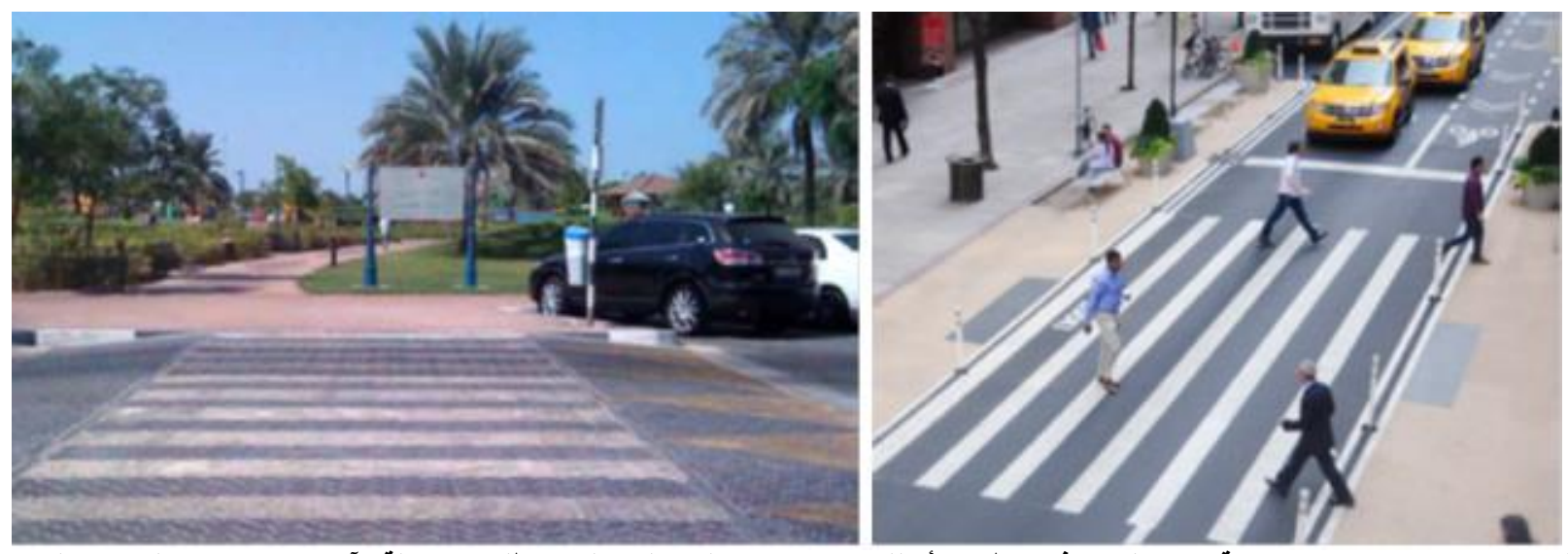

شكل (7): يوضح معبر مشاة بمدينة نيويورك يتو افق سطحه الأسفلتي مع مستوي الرصيف ويلبي منطلبات سهولة وآمان عبور جميع المشاة والسيارات

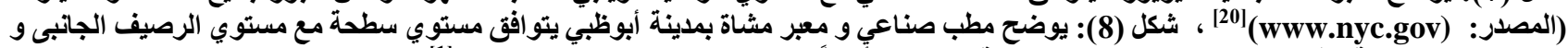

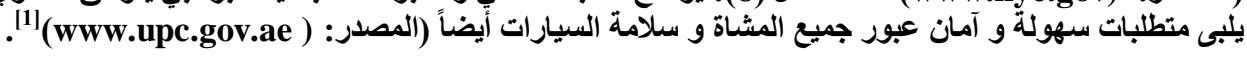

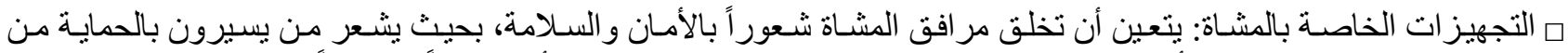

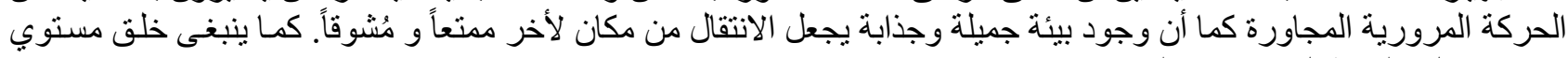
راحة مقبول علي طول مسار ات السير.

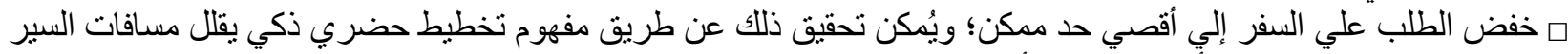

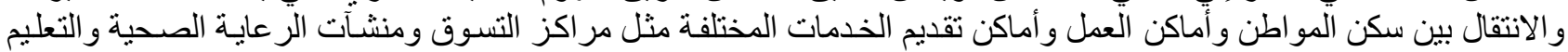

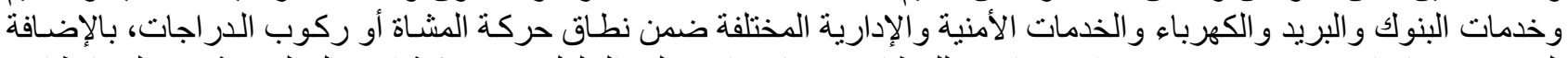

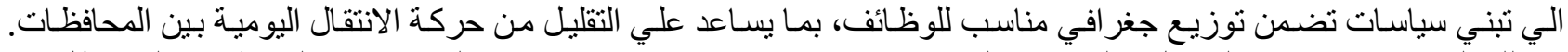

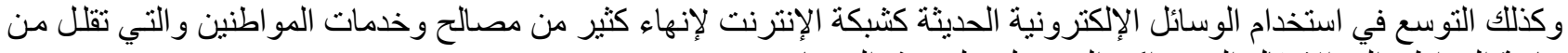

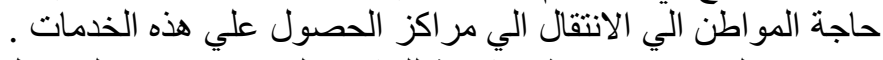

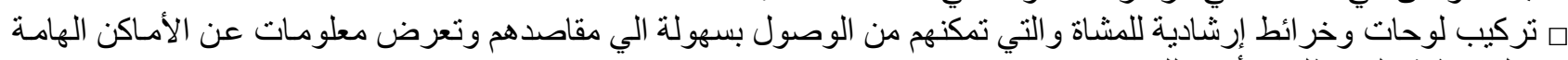

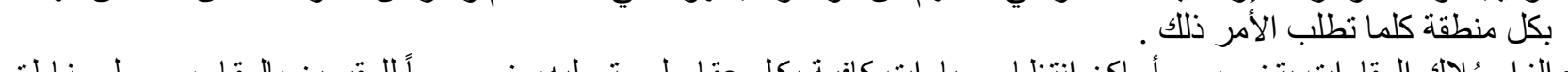

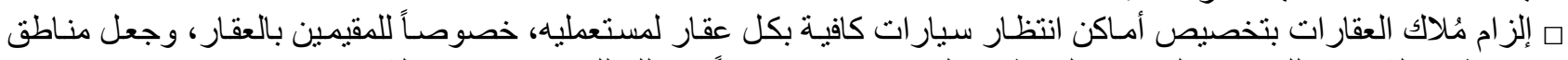

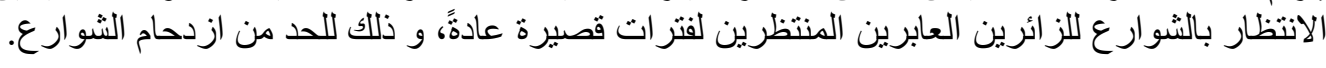

6

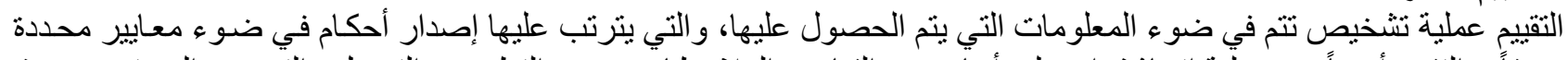

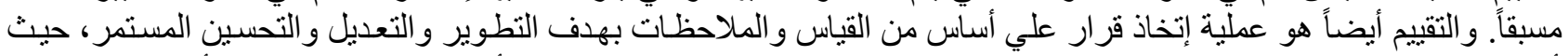

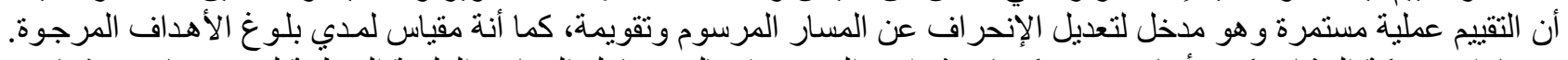

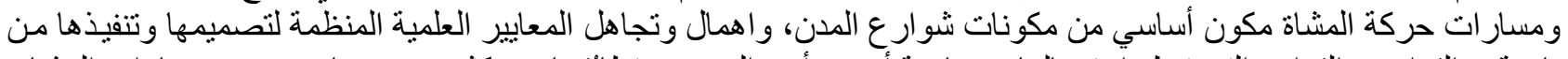

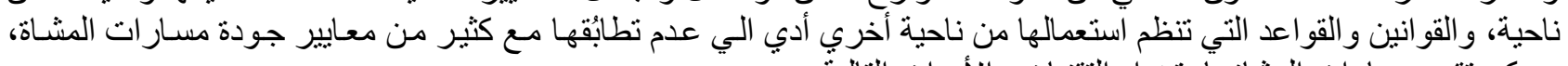

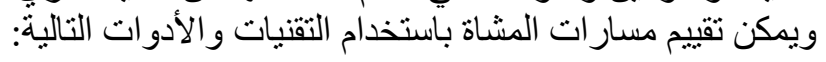

1-6

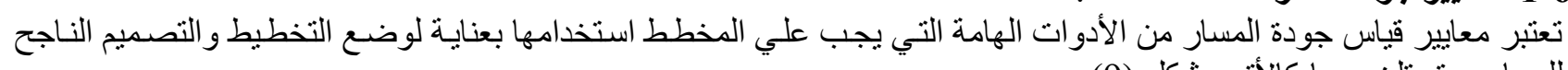

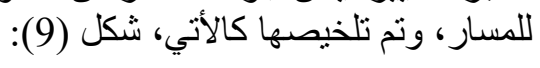

[4,2] 1-1-6 ه الأمان: يعني أمن وأمانئ المشاة عند استخدام المسار من مخاطر الحركة المروريـة أو من سوء صيانة أو توزيع عناصر فرش مسار المشاة. 
ه سهولة الوصول : سهولة وصول جميع مستعملي المسـار من و الي البيئة المحيطة بالمسـار، يعني ذلك سـهولة التنقل من نقطة بداية السير حتي الوصول : لألوص الي نقطة المقصد.

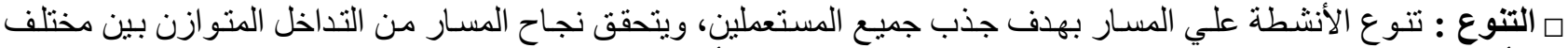

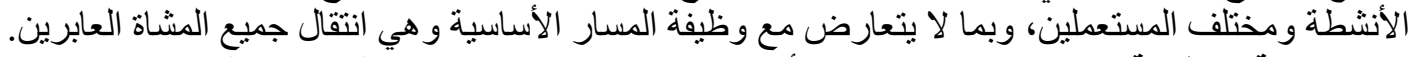

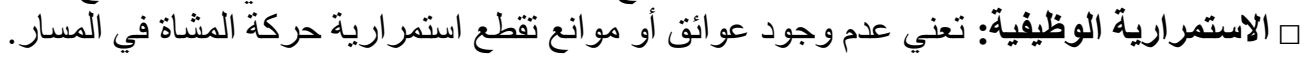

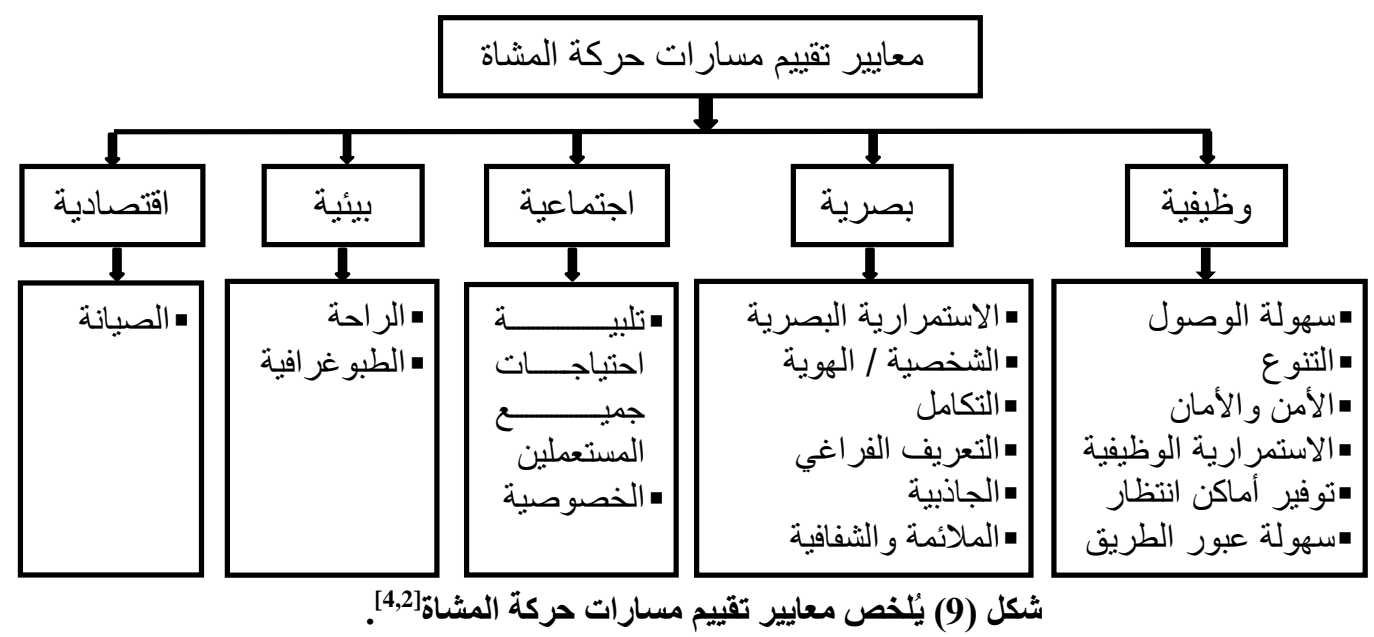

2-1-6

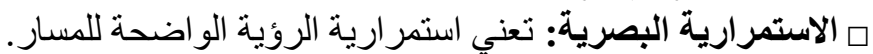

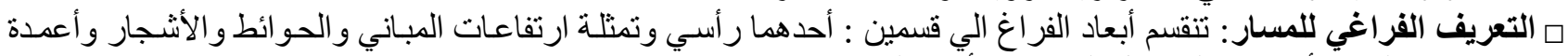

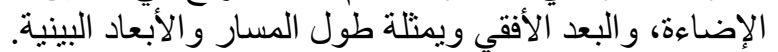

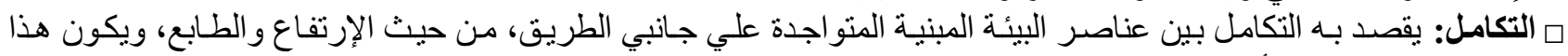

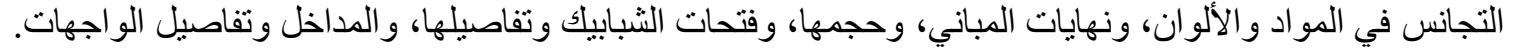

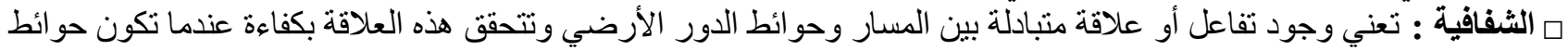

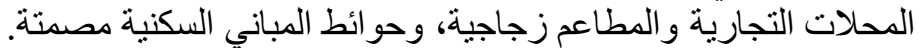
ه الثخصية : من الضروري أن يكون لكل موقع شخصيته التي تميزة عن غيره وئن ويمكن تحقيق ذلك من خلال تصميم المسار بحيث

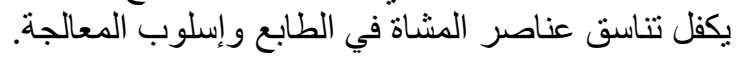

[4,2] 3-1-6

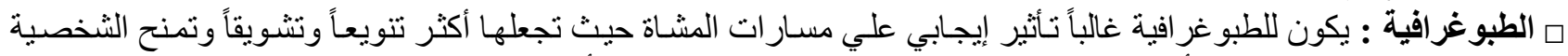

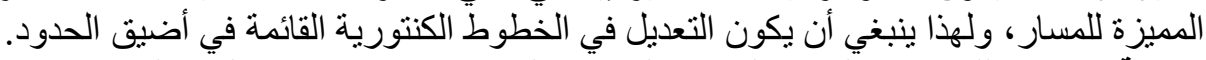

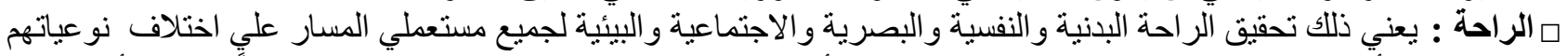

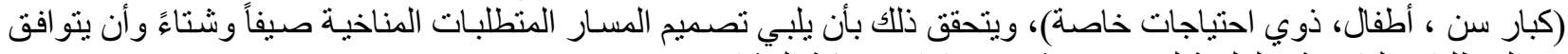

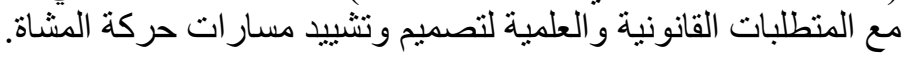

4-1-6 المعايير الاجتماعية:2,2]

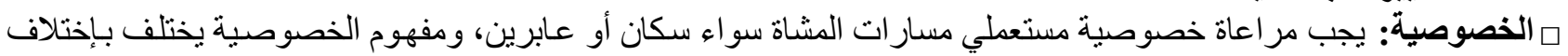

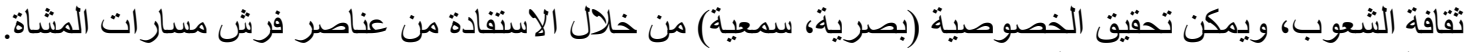

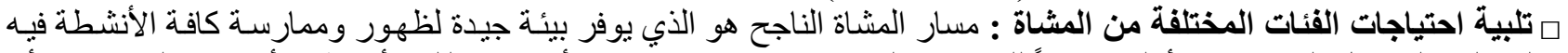

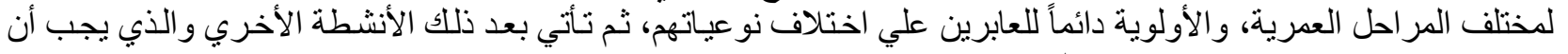
تؤخذ في الإعتبار عند تصميم مسار ات المشاة. 
5-1-6

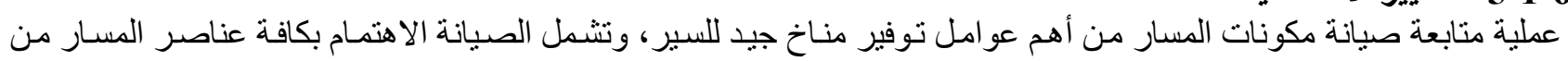
تشجير ومواد بناء وعناصر الفرش.

2- 6

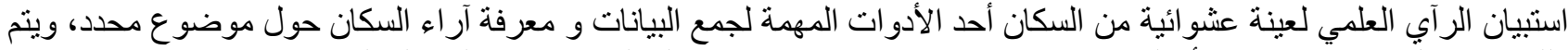

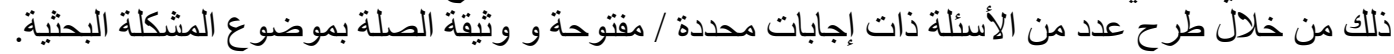

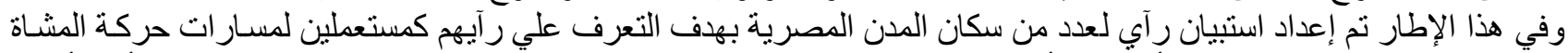

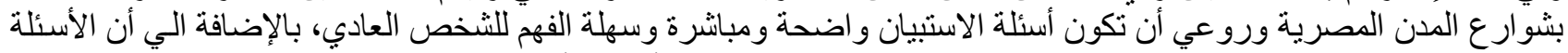

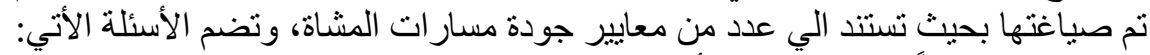

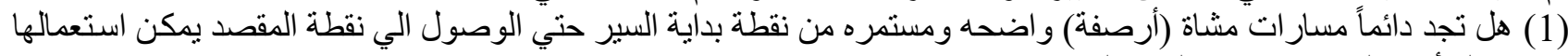

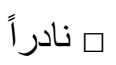
$V \square$

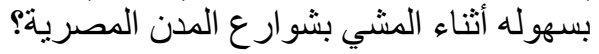

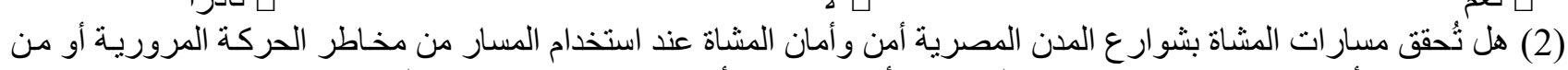

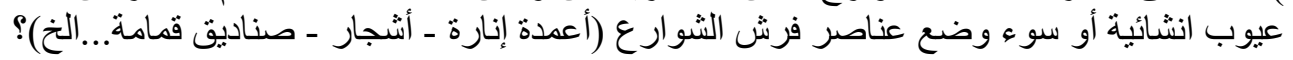

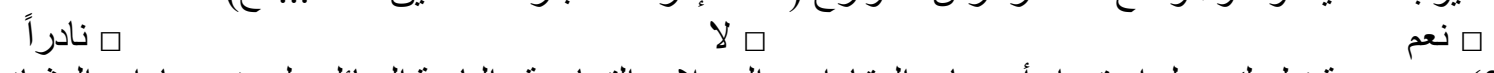

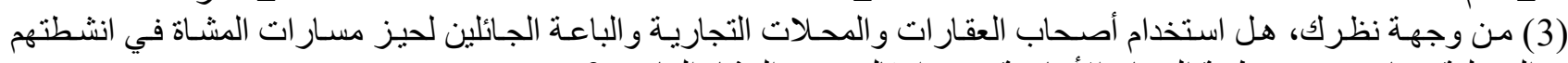
المختلفة يتعارض مع وظيفة المسار الأساسية وهي انتقاب التهار جميع المشاة العابرين؟

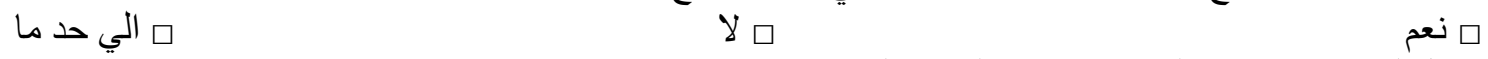

$$
\begin{aligned}
& \text { (4) هل لمسار ات حركة المشاة بشو ارع المدينة التي تسكن فيها طابع عمر اني خاص و شخصية تميز ها؟ }
\end{aligned}
$$

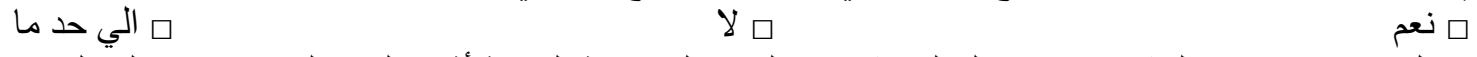

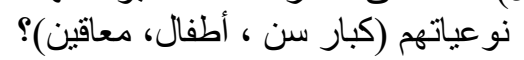

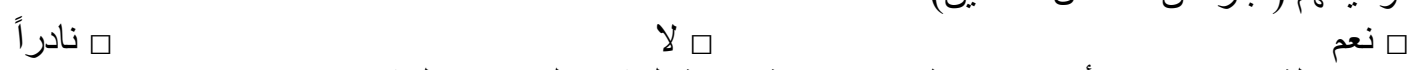

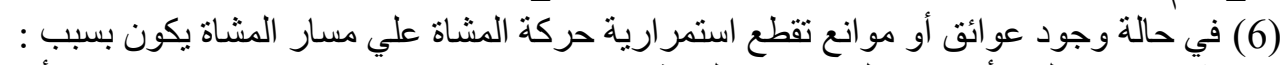

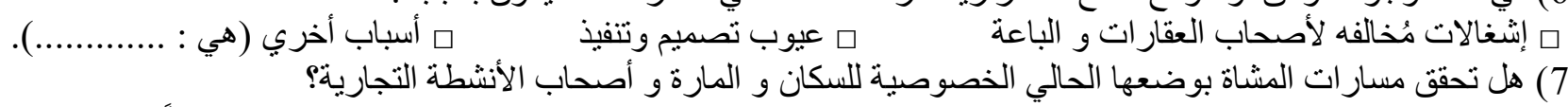

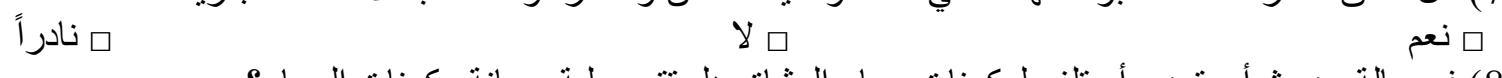
(8) في حالة حدوث أي تعدي أو تلف لمكونات مسار المشاة، هل تتم عملية صيانة مكونات المسار؟

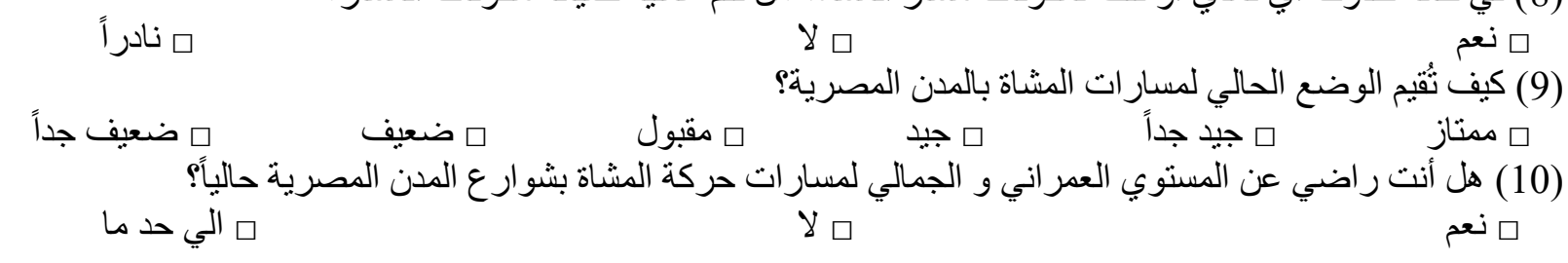

7 نتائج تقييم الوضع الحالي لمسارات المشاة بالمدن المصرية

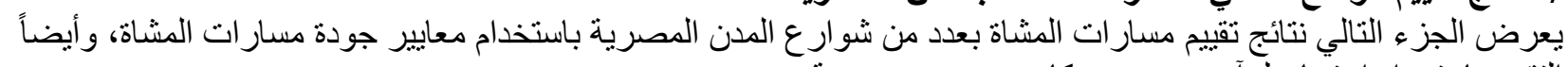

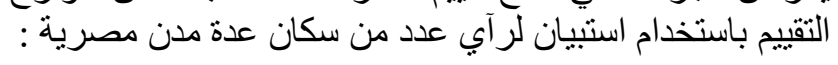

\section{1-7 نتائج التقييم باستخدام معاييز جودة مسارات المشاة (1) (المعانيير الوظيفية بائية}

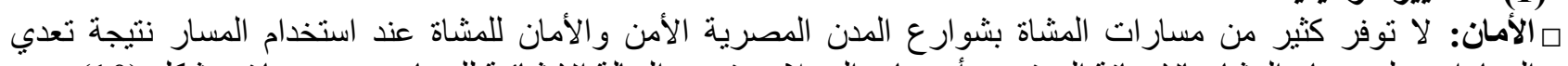

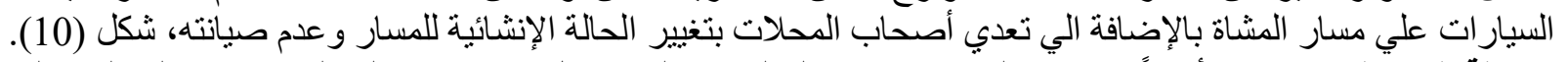

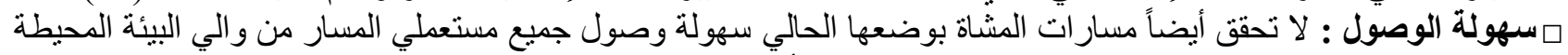
بالمسار، حيث يوجد حواجز و عر اقيل وتغيير لمنسوب المسار أمام مداخل المباني، شكل (11). 

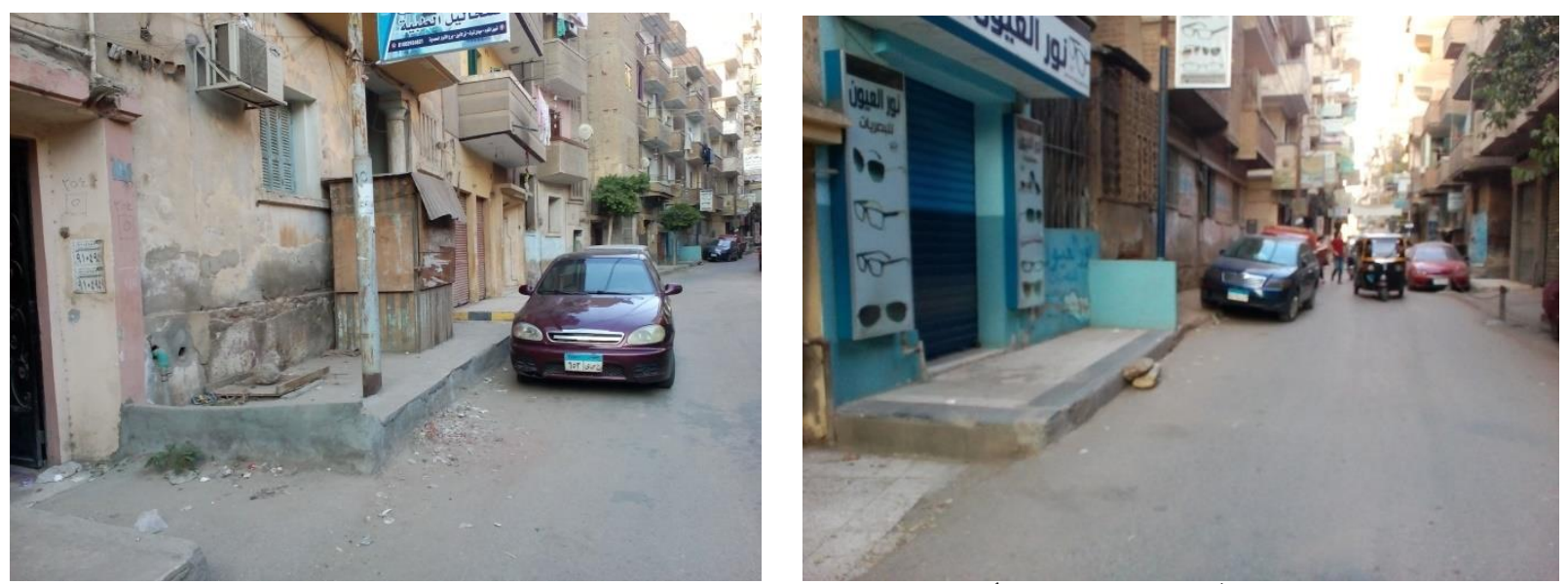

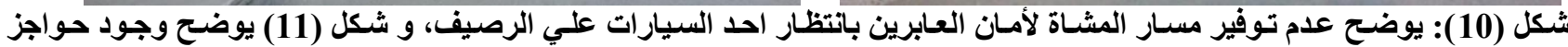
وعراقيل وتغيير لمنسوب المسار أمام مداخل المباني بشوان المارع مدينة شبين الكوم،(المصدر : "الباحث).

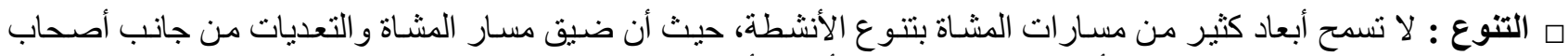

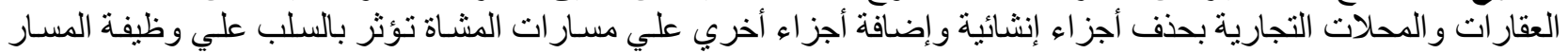

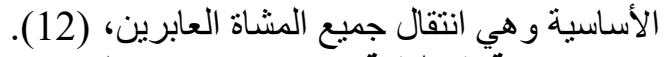

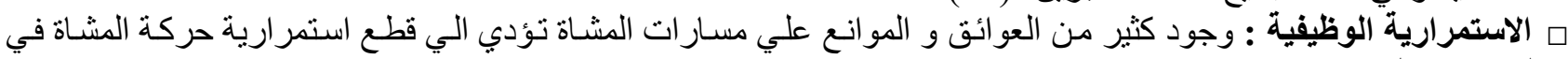

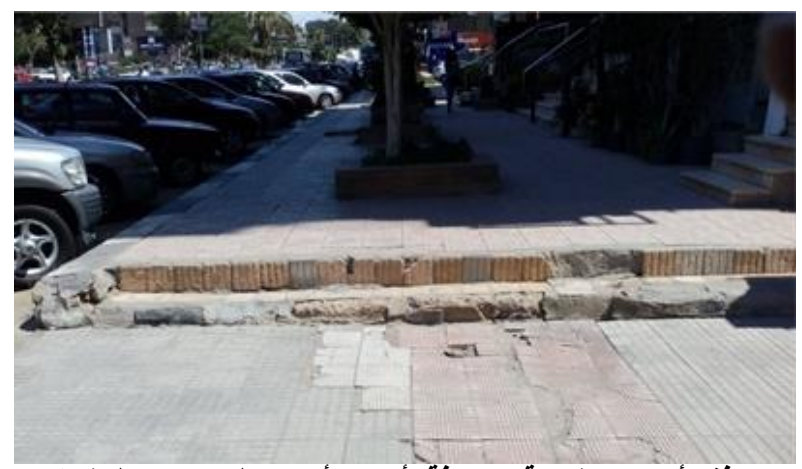

المسار ، شكل (13) - (13).

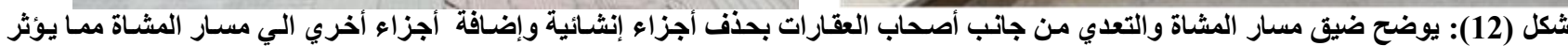

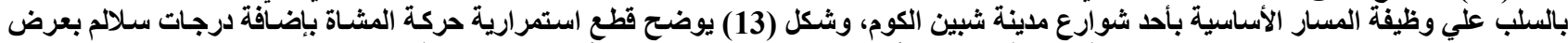
المسار مما يؤدي الي تغيير المنسوب و صعوبة الحركة لعربات الأطفال والمعاقين وكبار السن بأحد شوارع مدينة القاهرة، (المصدر:الباحث).

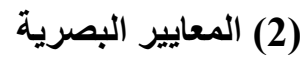

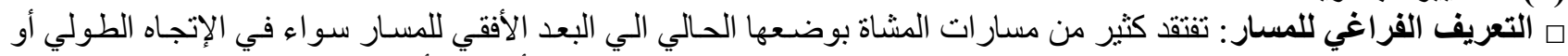

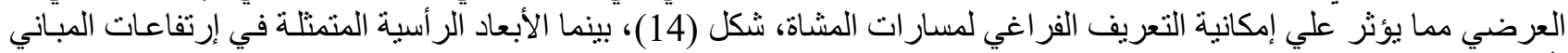

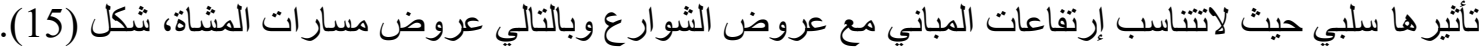

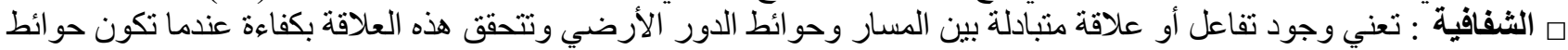

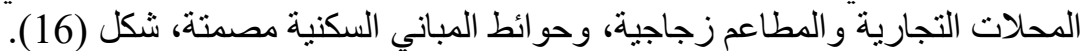

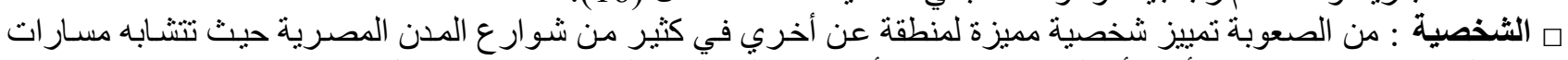

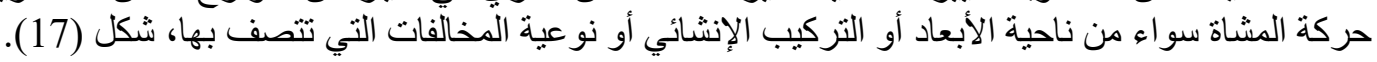



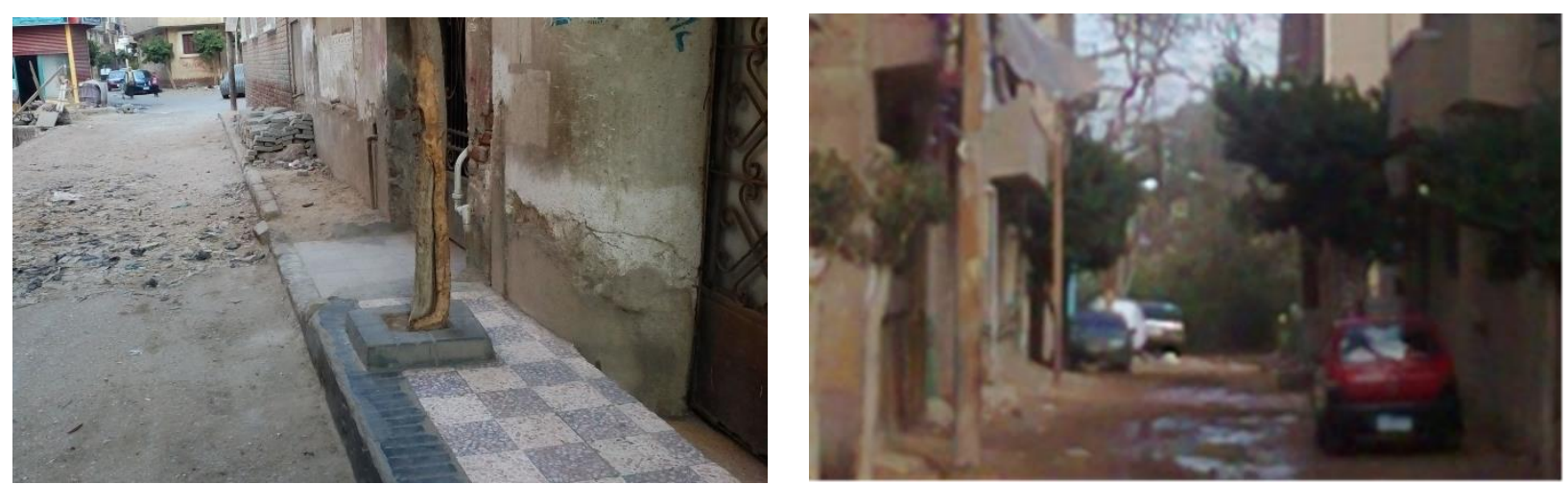

شكل (14) وشكل (15): عدم وجود البعد الأفقي للمسار سواء في الإتجاه الطولي أو العرضي مما يؤثر علي إمكاتية التعريف الفراغي لمستارات المشـاة،

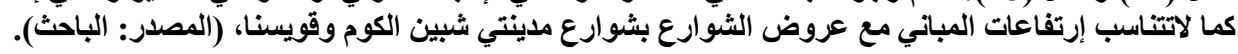
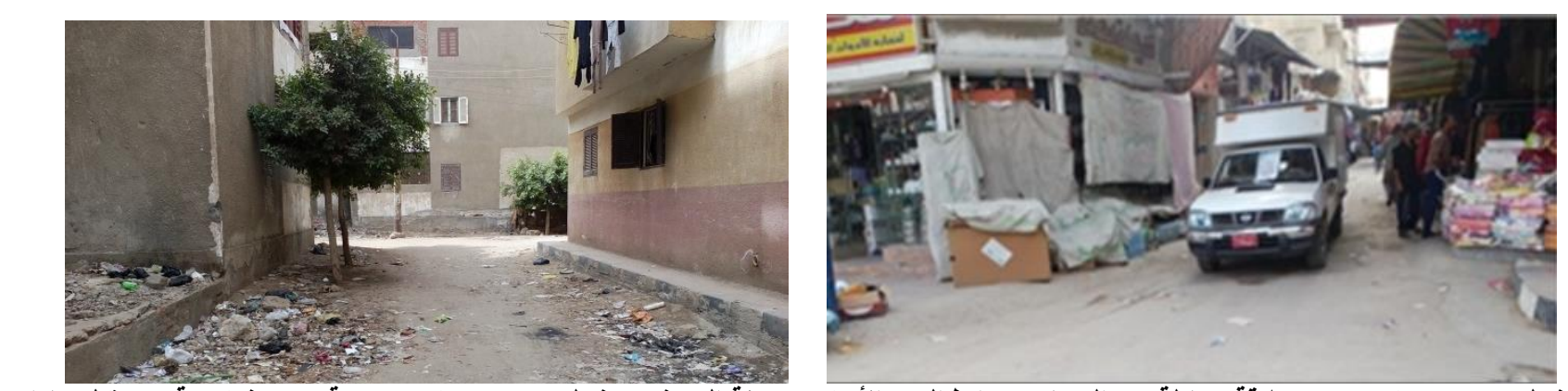

شكل (16) : يوضح وجود علاقة متبادلة بين المسار وحو ائط الدور الأرضي بمديذة العريش، وشكل (17): يوضح صعوبة تمييز شخصية مميزة لمسارات المشاة من منطقة لاخري في شوارع مدينة قويسنا، (المصدر: الباحث).

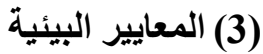

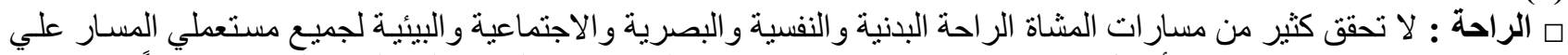

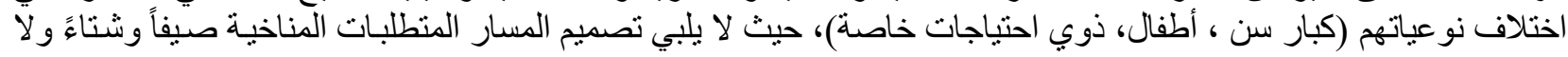

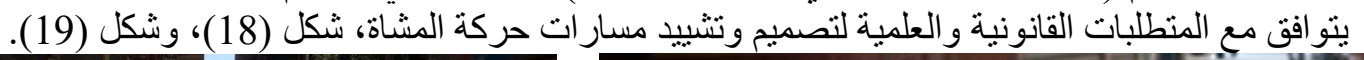
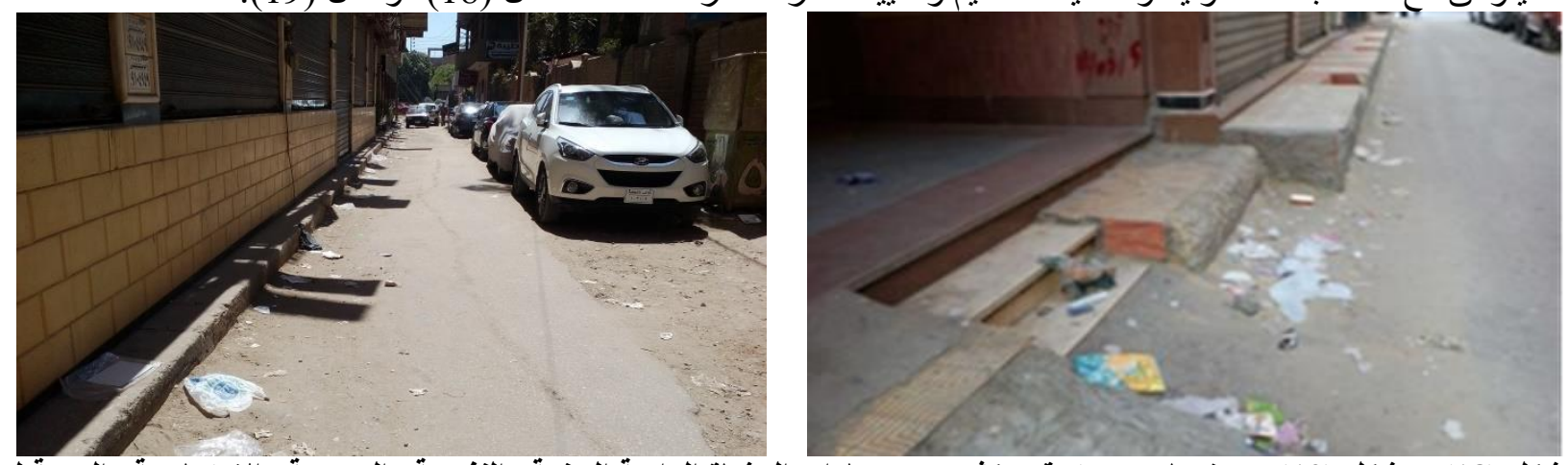

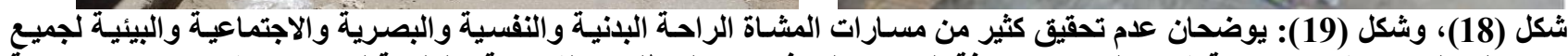

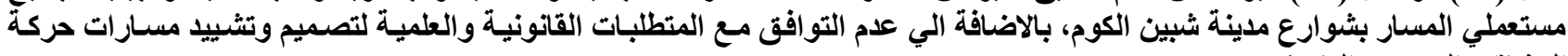
المشاة، (المصدر: الباحث).

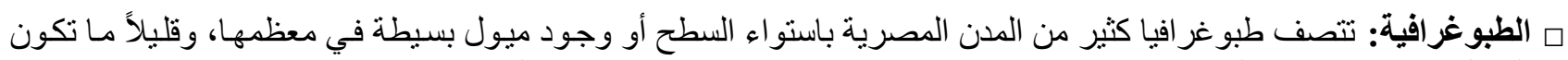

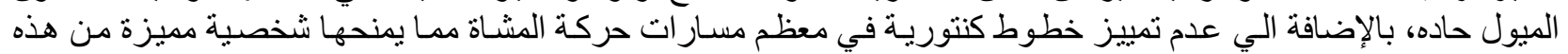
الناحية. 


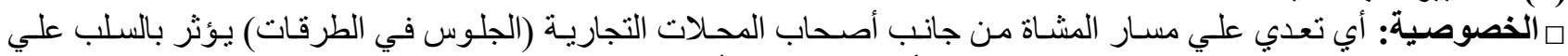

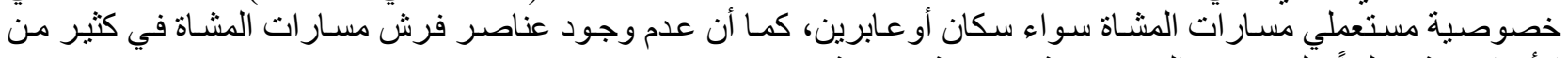
الأحيان يؤثر سلبياً علي تحقيق الخصار التصوصية (بصرية، سمعية).

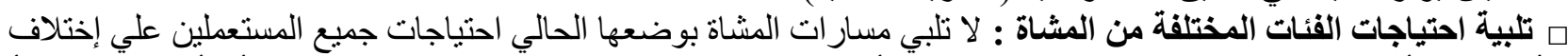

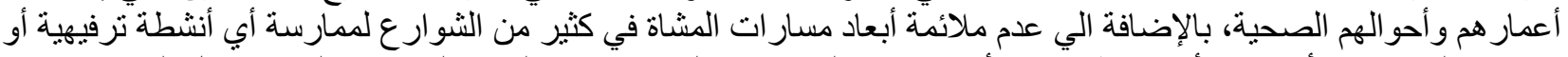

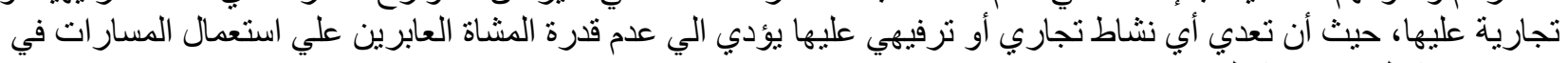

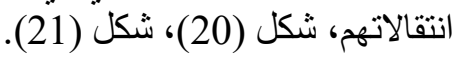
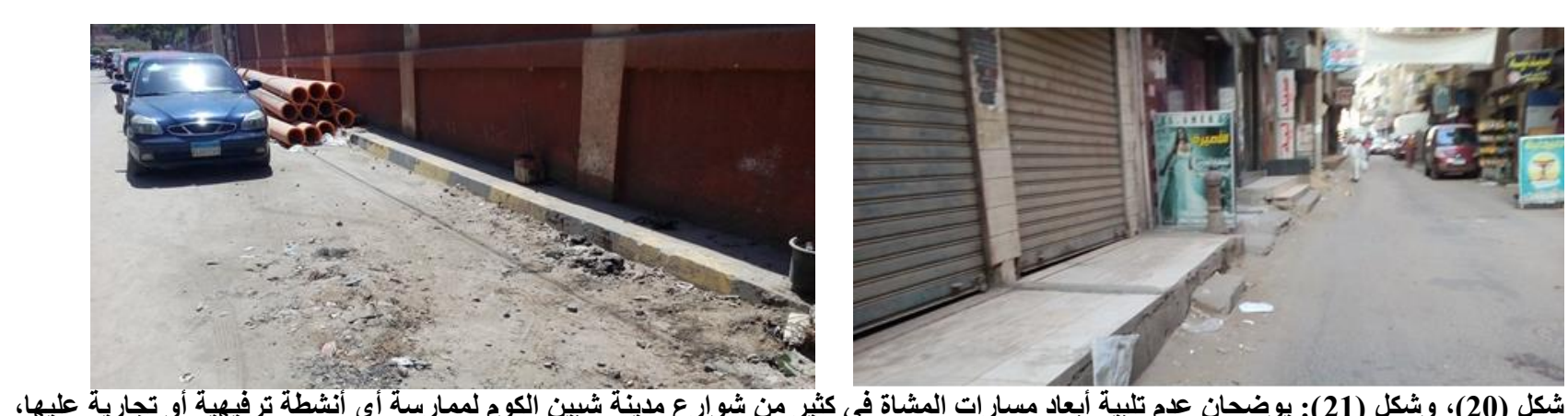

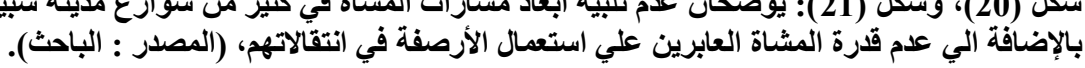

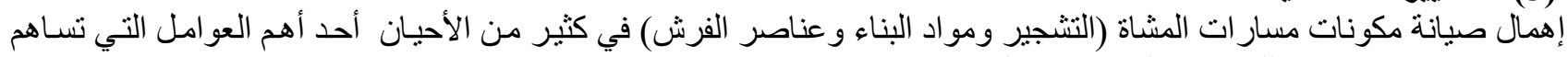

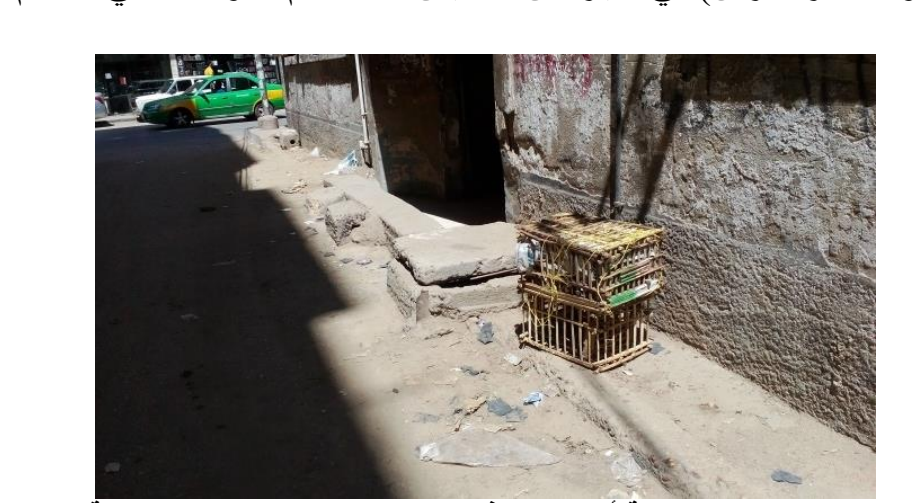

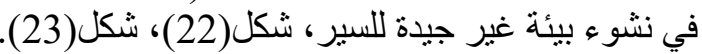

شكل (22) و شكل (23) : يوضحان إهمال صيانة مكونات مسار المشاة سواء المكونات الإنشائية أو عناصر فرش المسار بكثير من شوارع مدينة شبين الكوم، (المصدر : الباحث).

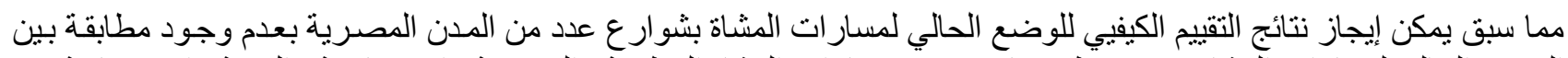

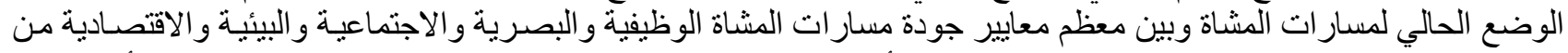

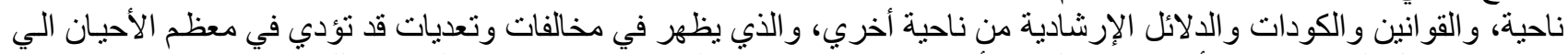

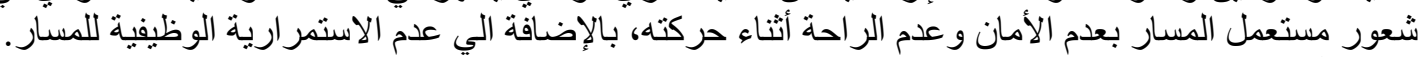

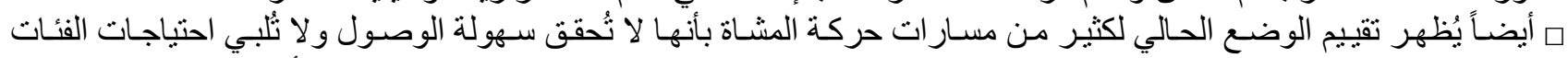

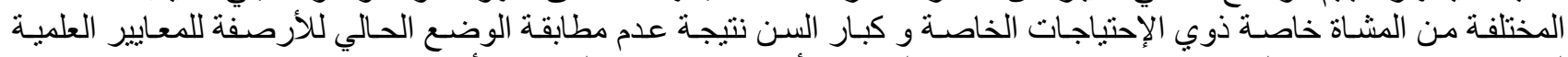

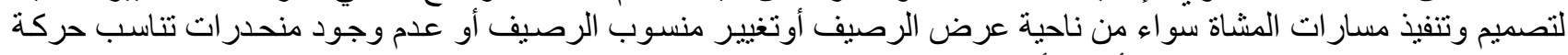
المعاقين في بداية ونهاية كل رصيف أو عند أماكن عبور المشاة بالتقاطعات الريف المرورية...الخ. 
2-7 نتائج استبيان رآي السكان

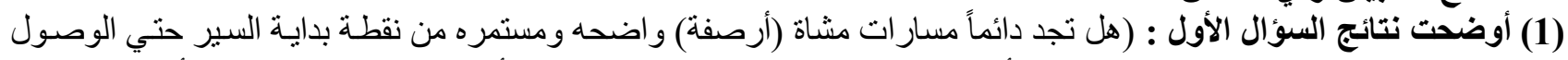

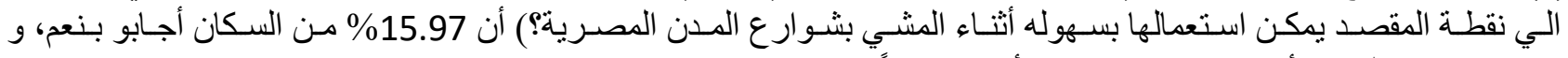

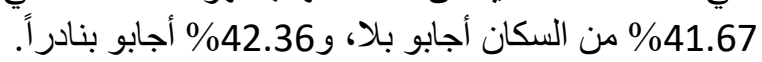

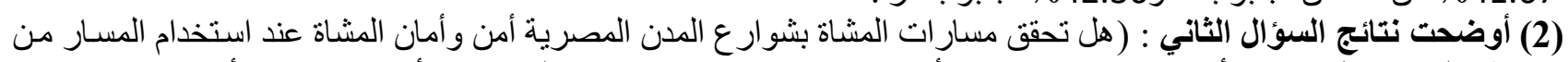

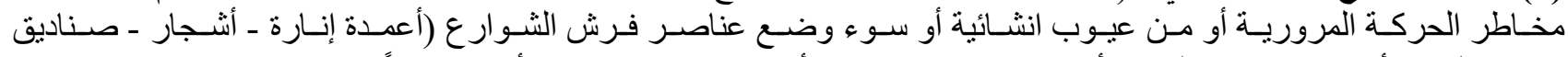

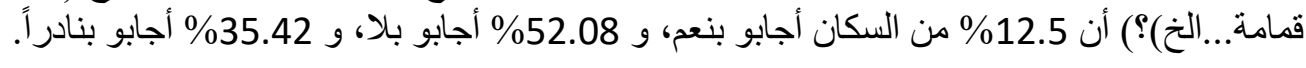
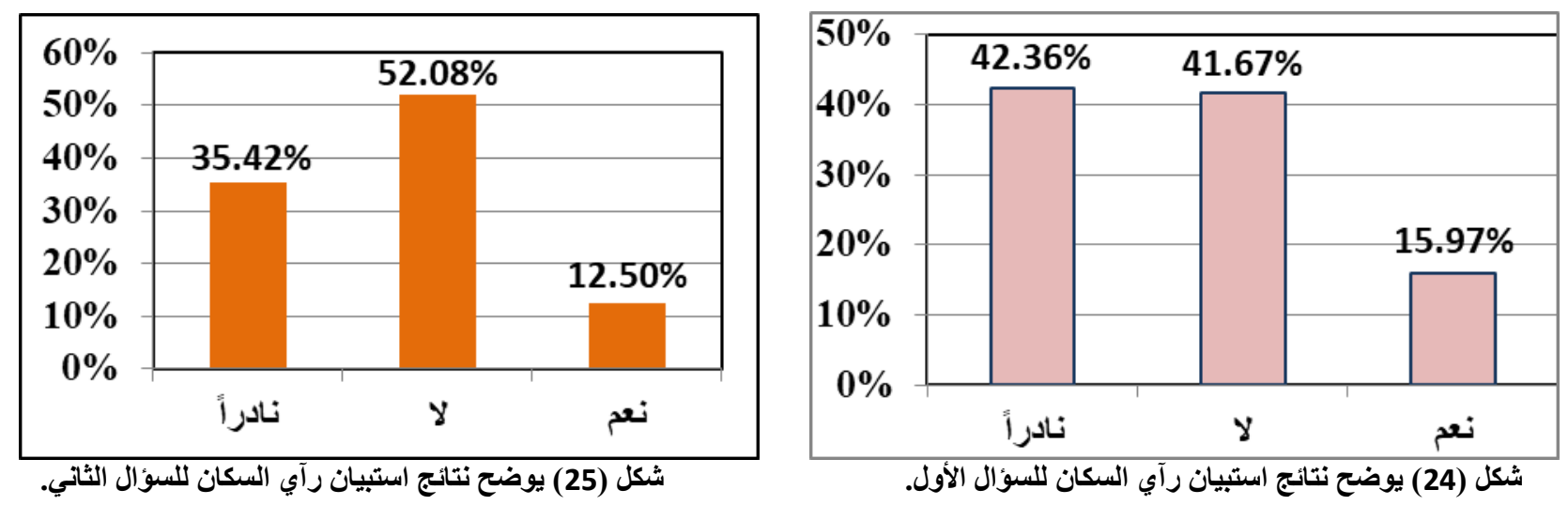

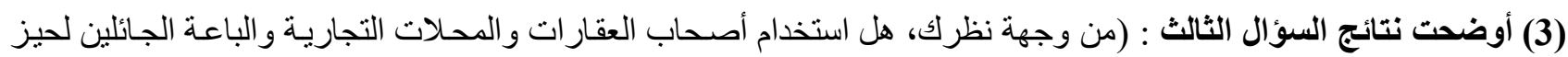

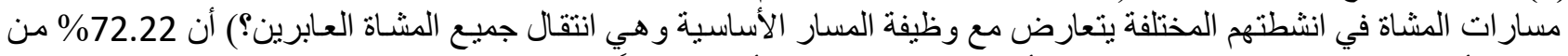

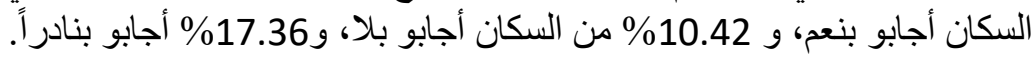

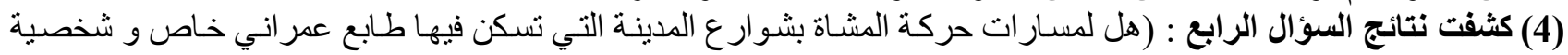

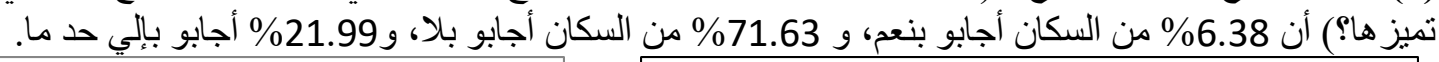
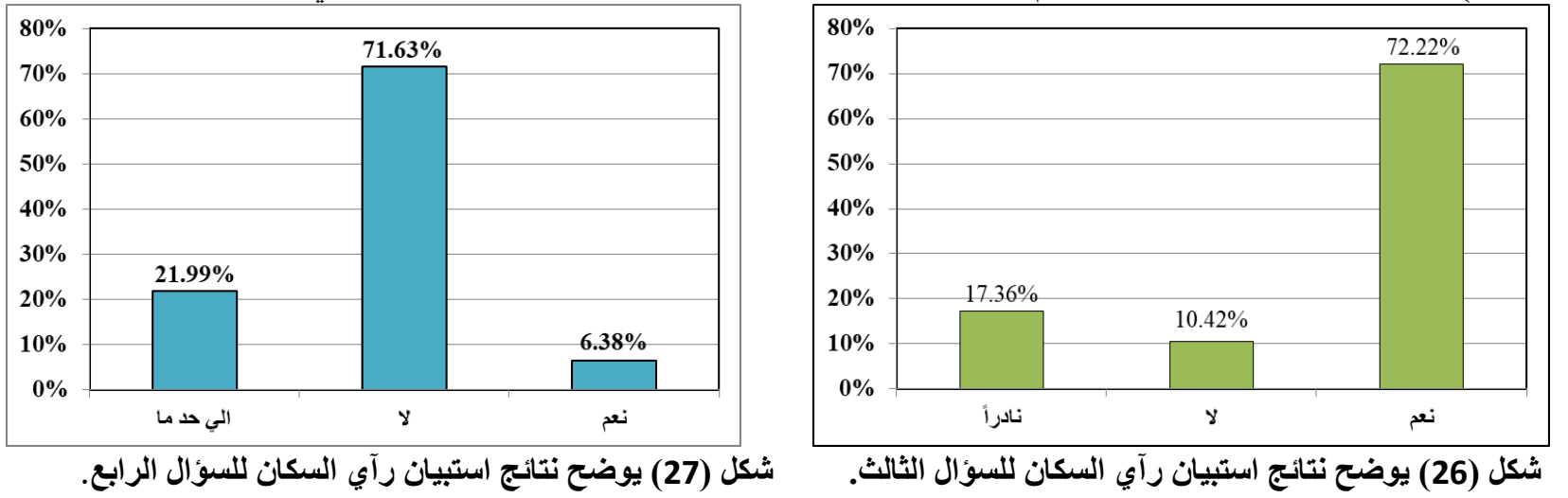

(5) أوضحت نتائج السؤال الخامس: هل تُحقق مسار ات المشاة بوضعها الحالي بشوار ع المدن المصرية الراحة أثناء السير لجميع

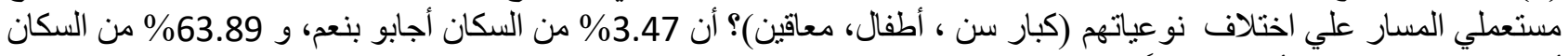

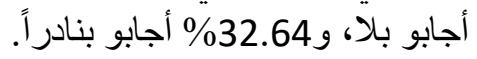

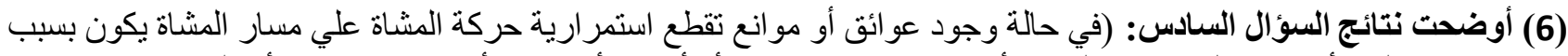

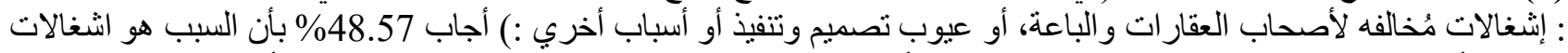

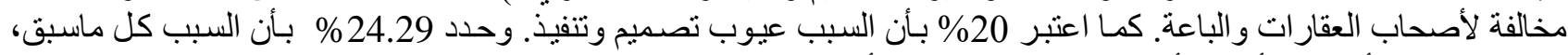

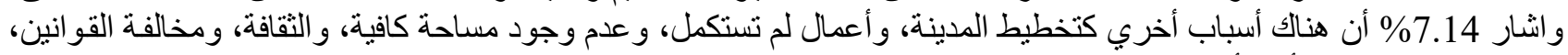
والتعدي علي حقوق الأخر أو الدولة. 


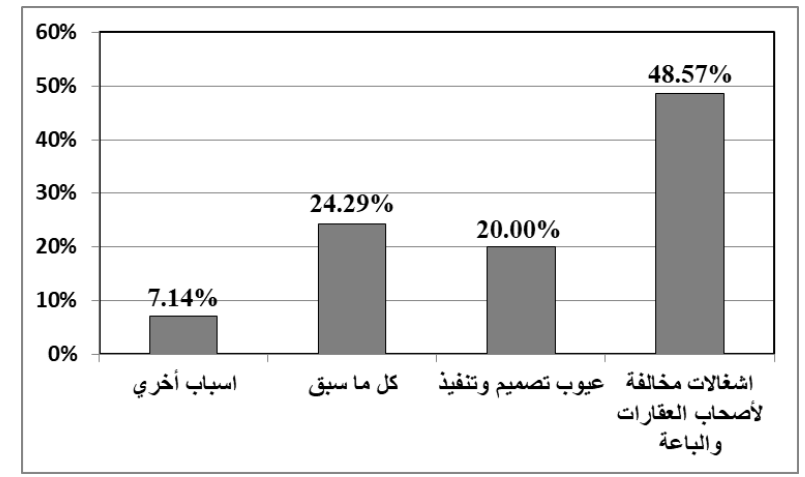

شكل (29) يوضح نتائج استبيان رآي السكان للسؤال السادس.

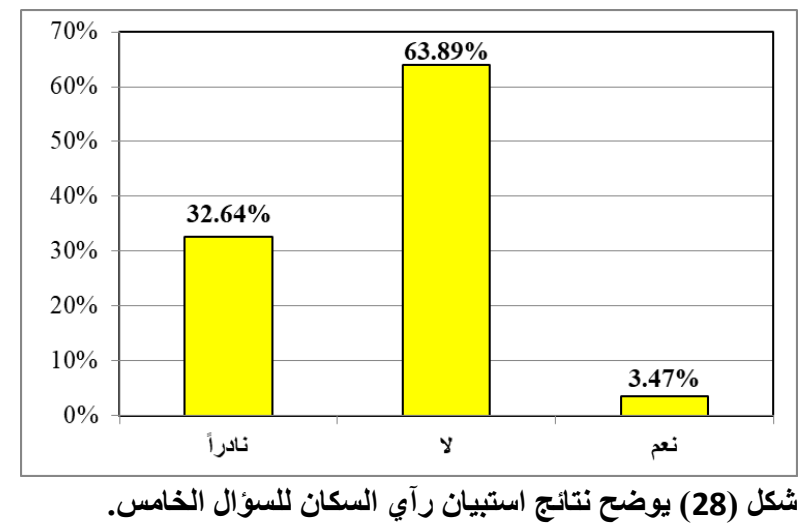

(5) أوضحث نتائج السؤال السـابع: هل تحقق مسـار ات المشـاة بوضـعها الحالي الخصوصية للسكان و المسارة و أصـحاب الأنثطة

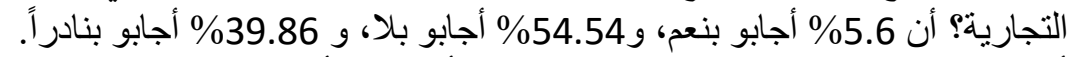

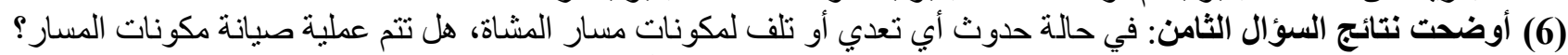

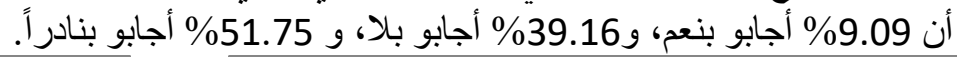
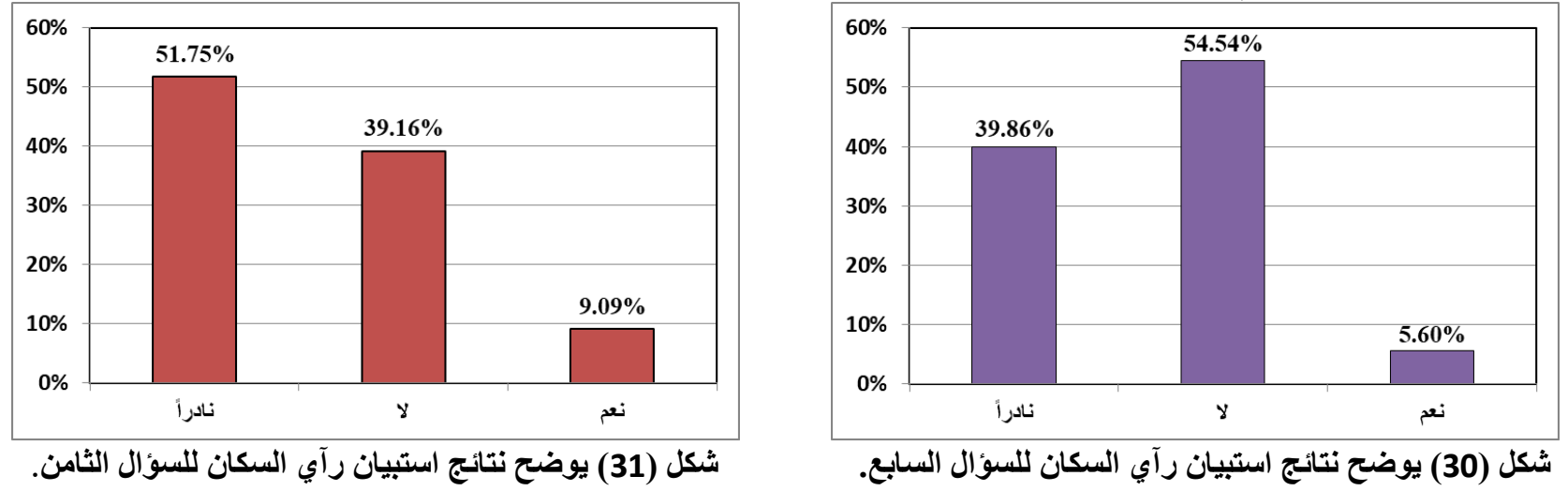

(7) أوضحت نتائج السؤال التاسـع: كيف تُقيم الوضـع الحسالي لمسـار ات المشـاة بالمدن المصرية؟ أن 0.69 \% أجـابو بممتاز ، و

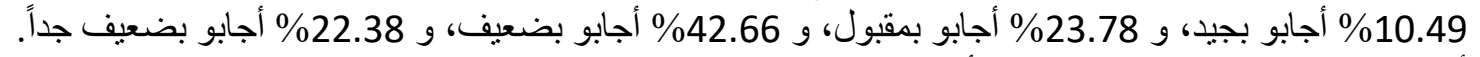

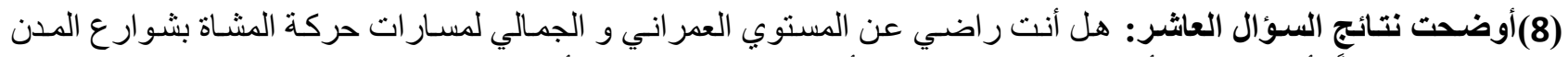
المصرية حالياًٌ أن 0.69 \% أجابو بنعم، و 63.89\% أجابو بلا، و \%35.42\% أجابو بإلي حد ما.
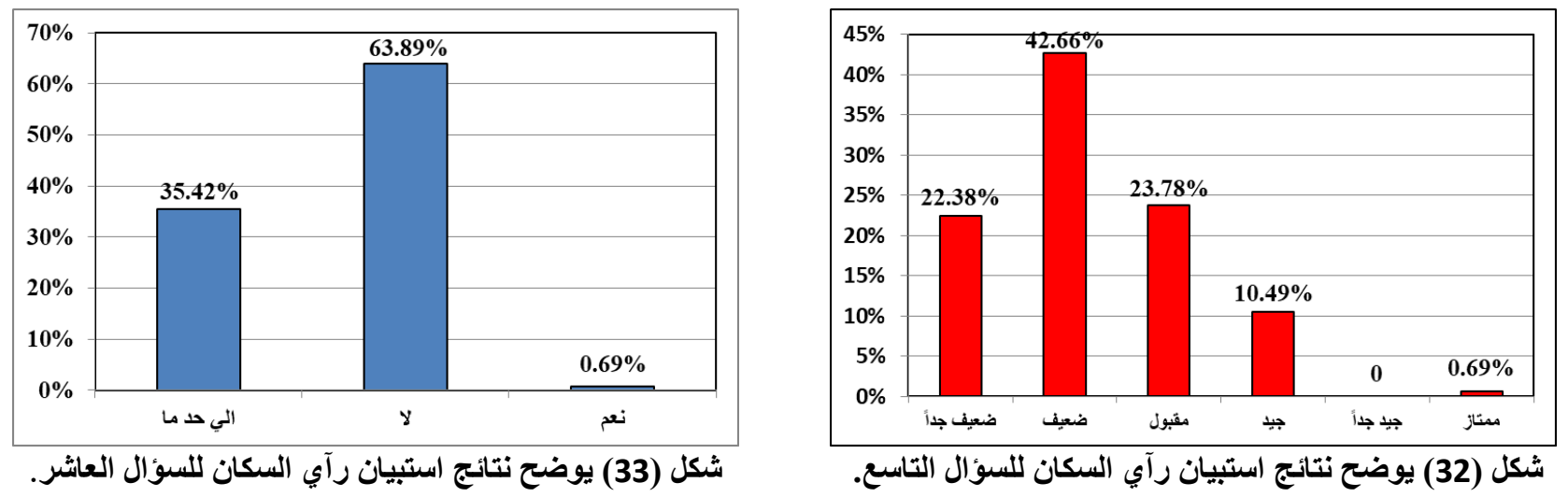
8

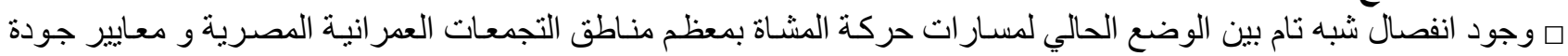

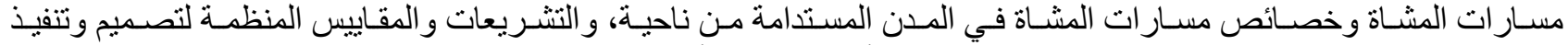

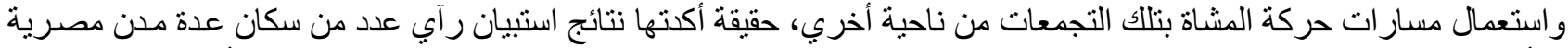

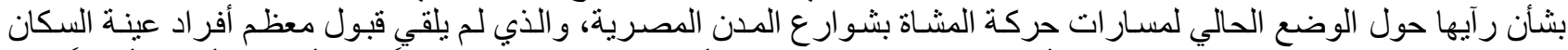

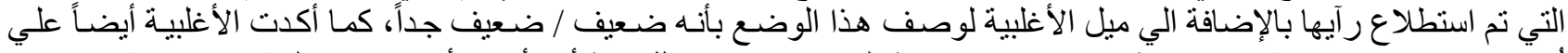

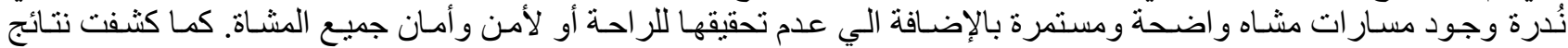

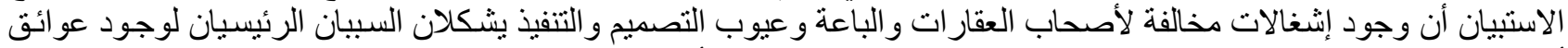

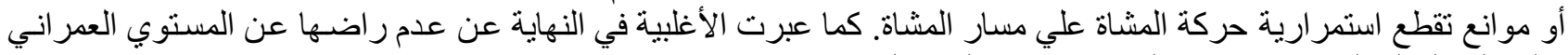

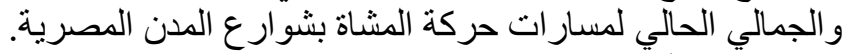

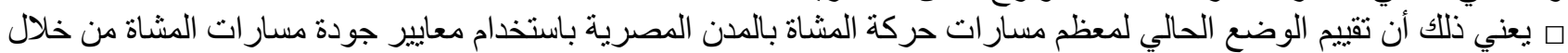

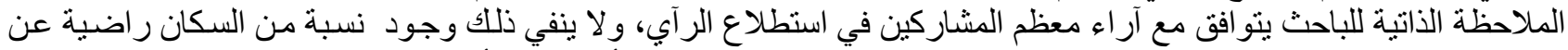

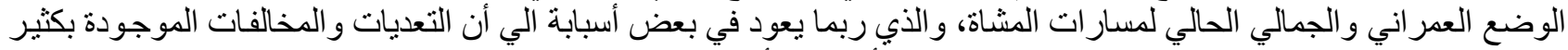

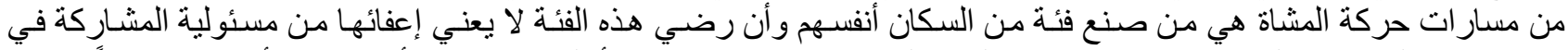

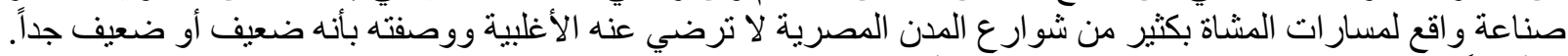

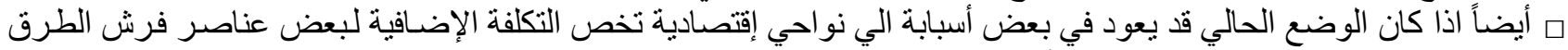

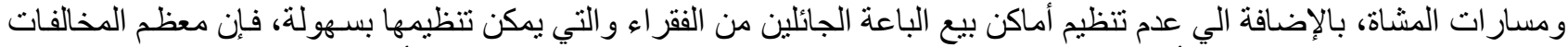

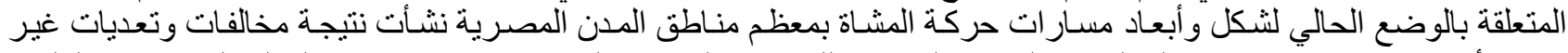

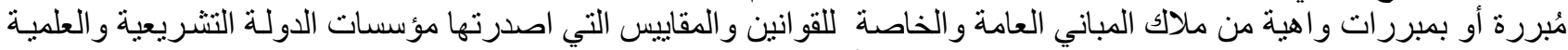

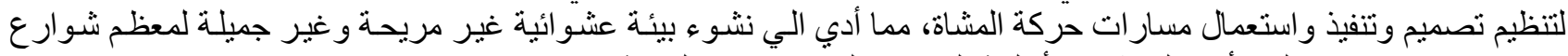

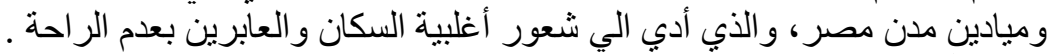

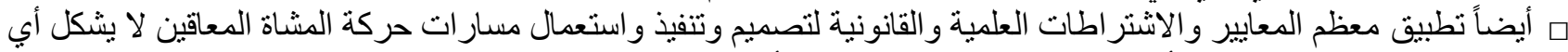

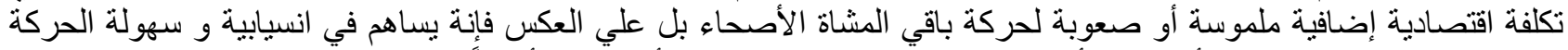

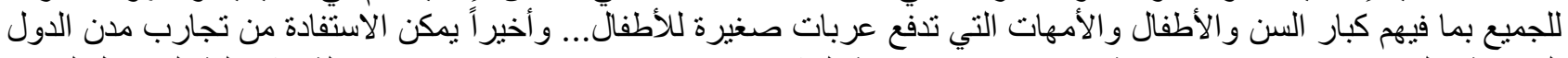

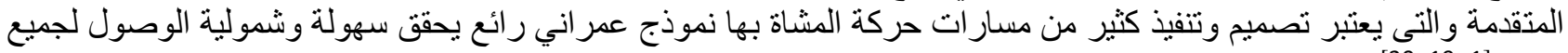

المشاة[1، 19، 20]

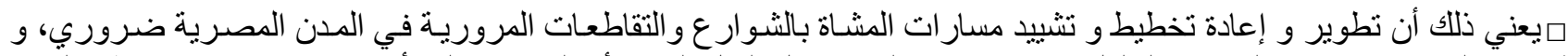

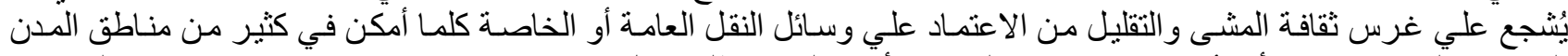

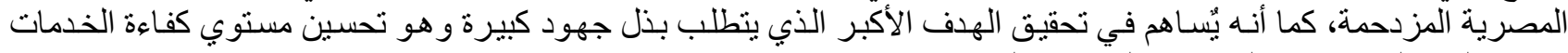

وجودة الحياة لكافة سكان التجمُعات العمر انية التهية المصرية.

9

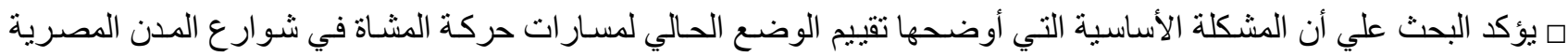

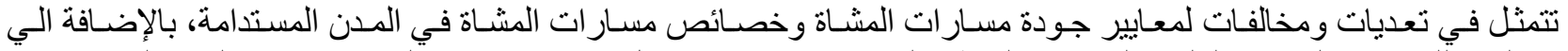

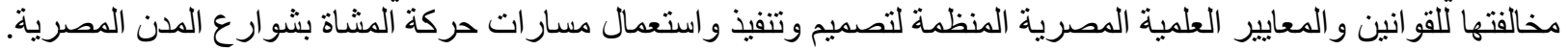

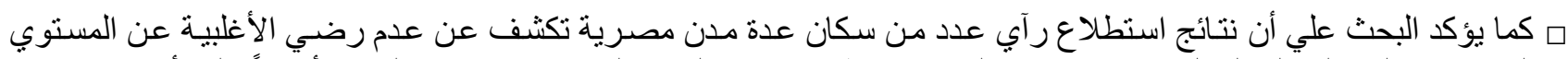

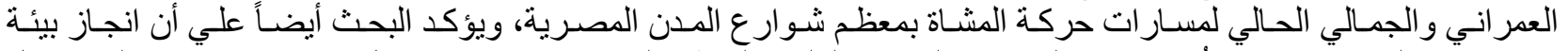

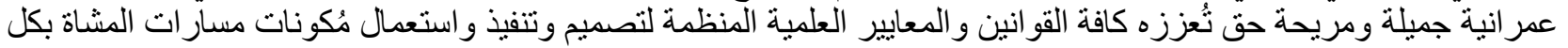
التجمعات العمر انية بمصر.

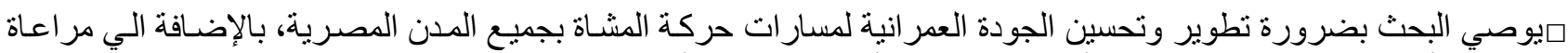

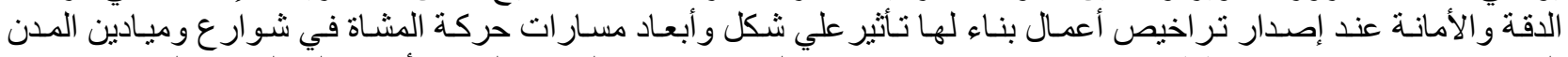

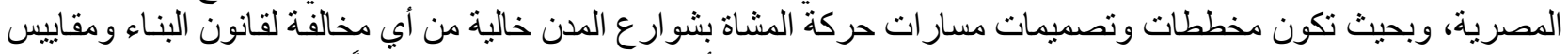

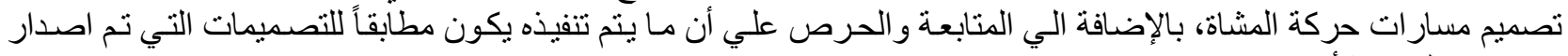
تز اخيص البناء بشأنها. 


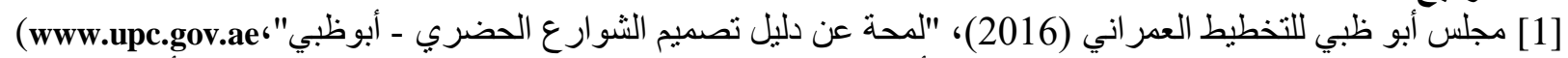

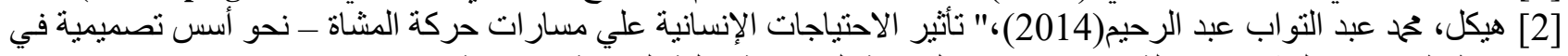

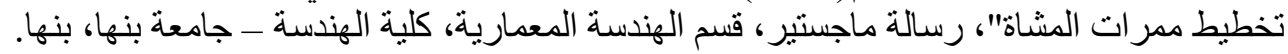

[3]Abdien, Nisreen Samy(2014), "Methodology for the evaluation of pedestrian walkways in gated communties", Dissertation, Architecture engineering department, Faculty of engineering, Cairo university, Cairo.

[4] شريف، محمد السيد عبد الرحمن(2010)، "الفكر التخطيطي لمسـار ات المشـاة في مدن الإنماء العقاري (دراسـة حالة)"، رسالة

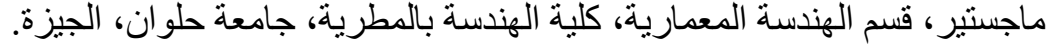

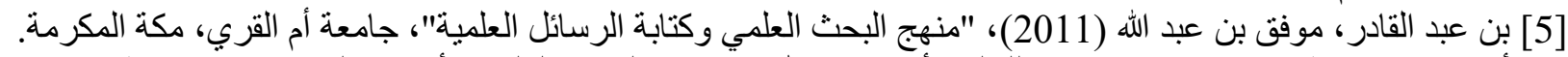

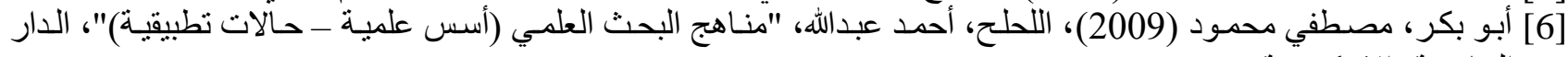
الجامعية، الإسكندرية.

[7] حسن، نشوي يوسف عبد الحئة الحافظ (2010)، "مؤشرات الاستدامة المجتمعية لمسار ات المشـاة (نحو مدخل للتقييم و القياس)"،

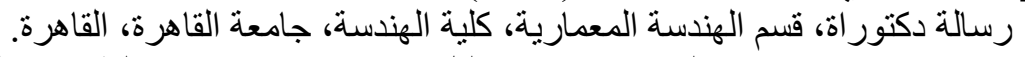

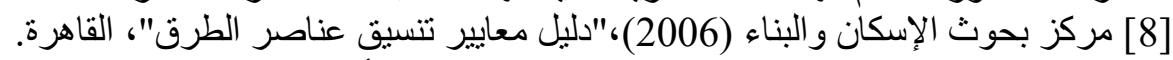

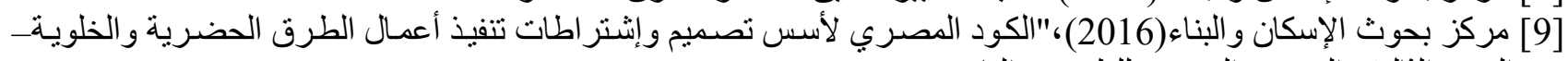

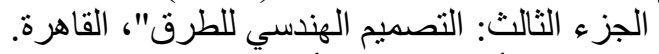

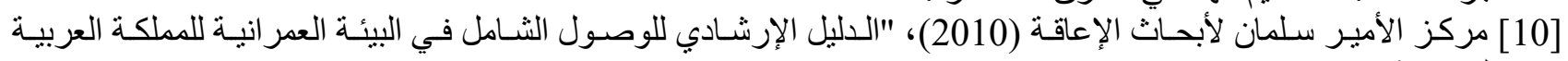
السعودية"، (www.kscdr.org.sa). [11] وز ارة الإسكان والمر افق والتنميـة العمر انية (2011)، "حالـة البيئة العمر انيـة ومؤشرات الإسكان بـالتطبيق علي سبع مدن مصرية "القادة القاهرة.

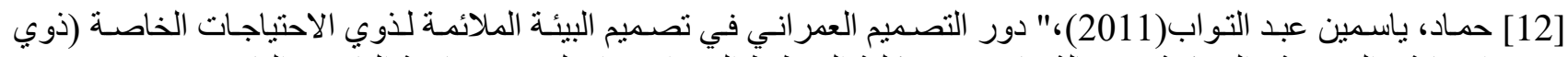

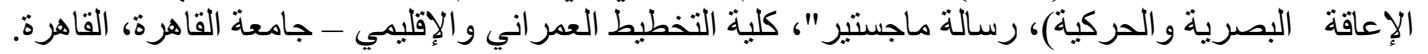

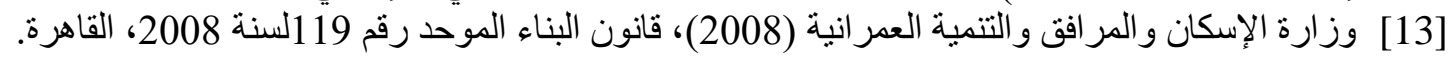

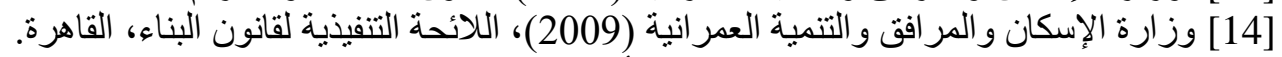

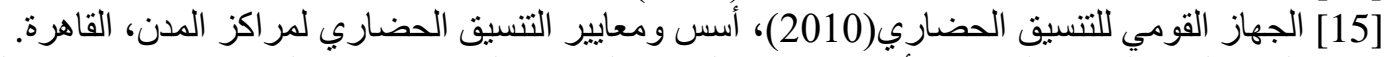

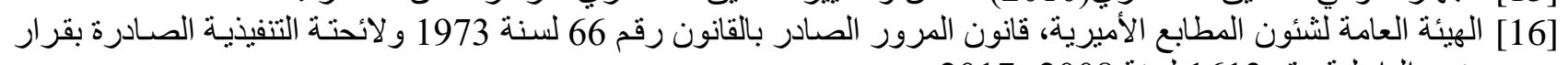

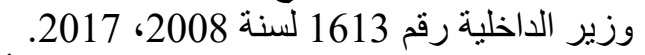

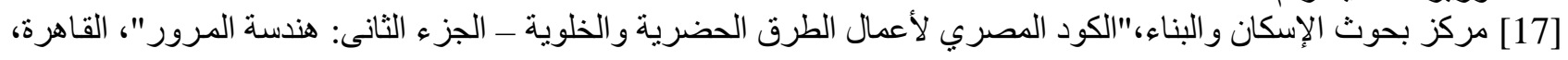
2008

[18] مركز بحوث الإسكان و البناء،"الكود المصري لتصميم الفراغات الخارجية والمباني لاستخدام المعاقين"، القاهرة، 2003.

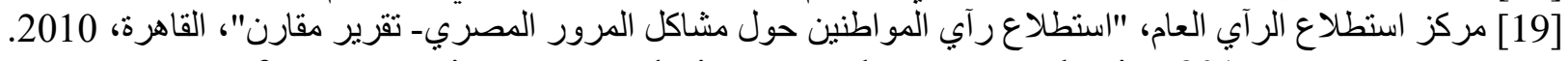
[20] Department of transportation, "Street design manual”, New York City, 2015. [21] مجلس أبو ظبي للتخطيط العمراني، " دليل تصميم الشوارع الحضرية ـ أبوظبي"، اصدار 1.1، (www.upc.gov.ae)، .2016 